\title{
DNORA3: A Nonhydrostatic High-Resolution Hindcast of the North Sea, the Norwegian Sea, and the Barents Sea
}

\author{
Hilde HaAkenstad, ${ }^{\mathrm{a}, \mathrm{b}}$ ØYvind Breivik, ${ }^{\mathrm{a}, \mathrm{b}}$ Birgitte R. Furevik, ${ }^{\mathrm{a}, \mathrm{b}}$ Magnar Reistad, ${ }^{\mathrm{a}}$ \\ PATRIK BOHLINGER, ${ }^{\mathrm{a}}$ AND Ole JOHAN AARnEs ${ }^{\mathrm{a}}$ \\ ${ }^{\text {a }}$ Norwegian Meteorological Institute, Oslo, Norway \\ ${ }^{\mathrm{b}}$ Geophysical Institute, University of Bergen, Bergen, Norway
}

(Manuscript received 18 February 2021, in final form 25 June 2021)

\begin{abstract}
The 3-km Norwegian Reanalysis (NORA3) is a 15-yr mesoscale-permitting atmospheric hindcast of the North Sea, the Norwegian Sea, and the Barents Sea. With a horizontal resolution of $3 \mathrm{~km}$, the nonhydrostatic numerical weather prediction model HARMONIE-AROME runs explicitly resolved deep convection and yields hindcast fields that realistically downscale the ERA5 reanalysis. The wind field is much improved relative to its host analysis, in particular in mountainous areas and along the improved grid-resolving coastlines. NORA3 also performs much better than the earlier hydrostatic 10-km Norwegian Hindcast Archive (NORA10) in complex terrain. NORA3 recreates the detailed structures of mesoscale cyclones with sharp gradients in wind and with clear frontal structures, which are particularly important when modeling polar lows. In extratropical windstorms, NORA3 exhibits significantly higher maximum wind speeds and compares much better to observed maximum wind than do NORA10 and ERA5. The activity of the model is much more realistic than that of NORA10 and ERA5, both over the ocean and in complex terrain.

SIGNIFICANCE STATEMENT: The 3-km Norwegian Reanalysis (NORA3) hindcast offers the first kilometer-scale climatological description produced with nonhydrostatic model physics of the North Sea, the Norwegian Sea, and the Barents Sea. With a horizontal resolution of $3 \mathrm{~km}$, the nonhydrostatic numerical weather prediction model resolves deep convection and yields hourly hindcast fields (2004-18) that realistically downscale the recent ERA5 reanalysis. The wind field is greatly improved relative to its host analysis, in particular in mountainous areas and along the improved gridresolving coastlines. NORA3 also performs much better than the earlier hydrostatic 10-km Norwegian Hindcast Archive (NORA10) in complex terrain. NORA3 is also better at reproducing the detailed structures of polar lows and comes closer to the maximum wind observed in extratropical windstorms than do NORA10 and ERA5.
\end{abstract}

KEYWORDS: Arctic; North Atlantic Ocean; Wind; Climatology; Storm environments; Nonhydrostatic models; Reanalysis data; Coastal meteorology; Mountain meteorology; Orographic effects; Wind effects

\section{Introduction}

High-resolution atmospheric hindcast archives are essential to assessing the detailed wind climate in the coastal zone and in complex terrain. They also provide forcing for nearshore wave hindcasts (Gaslikova and Weisse 2006; Breivik et al. 2009; Christakos et al. 2020a,b). Although global atmospheric reanalyses with sophisticated data assimilation systems yield the best possible overall accounts of past synoptic weather situations, their resolution is too coarse to adequately resolve mesoscale features. The latest reanalysis from the European Centre for Medium-Range Weather Forecasts (ECMWF), ERA5, has a horizontal resolution of $31 \mathrm{~km}$ (Hersbach et al. 2020) and a vertical resolution of 137 levels. Other recent reanalyses, such as MERRA (Rienecker et al. 2011) and the NCEP Climate Forecast System Reanalysis (CFSR; Saha et al.

Denotes content that is immediately available upon publication as open access.

Breivik's ORCID: 0000-0002-2900-8458.

Corresponding author: Øyvind Breivik, oyvind.breivik@met.no
2010) and its updated version 2, CFSRv2 (Saha et al. 2014), as well as the older ECMWF analyses ERA-40 (Uppala et al. 2005) and ERA-Interim (Dee et al. 2011), have horizontal resolutions ranging from about $50 \mathrm{~km}$ to $1.5^{\circ}$. The resolution of such global reanalyses is generally so coarse that winds in extratropical systems tend to be biased toward lower values (Hodges et al. 2011). This makes them unsuitable for studies of mesoscale phenomena, both marine and terrestrial [see Moore et al. (2015) and Moore et al. (2016) for a detailed account of the impact of resolution on the topographic flow in complex terrain]. Mesoscale polar lows (Rasmussen and Turner 2003; Føre et al. 2011) are not even properly modeled at a resolution of $10 \mathrm{~km}$ (Reistad et al. 2011; Haakenstad et al. 2020). It is also evident that extremes will be biased toward lower values in global reanalyses, whether these are related to synoptic or mesoscale systems (Breivik et al. 2013, 2014; Breivik and Aarnes 2017; Meucci et al. 2018; Takbash et al. 2019).

From a practical point of view, extreme value estimates and other statistics of marine wind and wave climate are crucial for the assessment of safe shipping (Bitner-Gregersen et al. 2018), wind energy assessment (Furevik and Haakenstad 2012) and construction of coastal and offshore structures (Donelan and Magnusson 2017; Gramstad et al. 2018). It is therefore important that biases in the upper percentiles of hindcasts and 
reanalyses used for extreme value estimation are properly accounted for.

Long-term historical archives of extremes are also important for gauging changes in marine wind and wave climate, even if trends are notoriously difficult to assess from reanalyses (Aarnes et al. 2015; Meucci et al. 2020). While there is a growing consensus that an increase in wind speed and wave height is likely in the southern extratropics under a warmer climate (Morim et al. 2019), it is still unclear how the wind climate in the northern extratropics will change in the future (Shimura et al. 2016; Aarnes et al. 2017; Bricheno and Wolf 2018; Catto et al. 2019; Morim et al. 2019).

The model performance in this hindcast study is measured primarily in terms of surface wind speed. This has a practical motivation, because the $10-\mathrm{m}$ wind is the single most important parameter for marine and coastal climate and is the only atmospheric variable to directly affect a wave model.

Covering the North Sea, the Norwegian Sea, and the Barents Sea, the nonhydrostatic $(\mathrm{NH})$ convection-permitting numerical weather prediction (NWP) model, HIRLAMALADIN Research on Mesoscale Operational NWP in Euromed-Applications of Research to Operations at Mesoscale (HARMONIE-AROME) has been set up on a 3-km horizontal resolution grid with 65 vertical levels. ERA5 reanalysis fields (Hersbach et al. 2020) provided the initial and boundary conditions. In addition, a surface analysis was performed to refine the initial conditions of each integration cycle. Utilizing a highresolution nonhydrostatic NWP model such as HARMONIEAROME allows modeling of atmospheric features having comparable scales in the vertical and horizontal dimension. Thunderstorms, squall lines, and orographically induced gravity waves are examples of features requiring the full nonhydrostatic equations to be modeled realistically.

This article is organized as follows: The HARMONIEAROME model setup and its ERA5 boundary conditions are presented in section 2. Results from the 15-yr hindcast integration are presented and its performance in coastal, maritime, and mountain regions assessed in section 3. Section 4 discusses the findings and the applicability of the archive for estimates of mean and extreme wind climatology.

\section{Model setup}

The nonhydrostatic convection-permitting numerical weather prediction model HARMONIE-AROME, Cy 40h1.2, is used in the downscaling of the ERA5 reanalyses. AROME takes its adiabatic part from the nonhydrostatic ALADIN model (Bubnová et al. 1995; ALADIN International Team 1997; Bénard et al. 2010) and its physical parameterizations from Meso-NH (Lafore et al. 1998). The AROME model has been running operationally as the national short range model by Météo-France since December 2008. The fundamentals of AROME are described by Seity et al. (2011) and Brousseau et al. (2016). The HARMONIE-AROME version is developed and maintained as part of the shared ALADIN-HIRLAM system (Bengtsson et al. 2017). The HARMONIE-AROME became operational for the Nordic Meteorological Cooperation on Operational Numerical Weather Prediction (MetCoOp) domain in 2013 (Müller et al. 2017b) and an extended version (AROME-Arctic) is also running operationally for the Arctic domain (Müller et al. 2017a). The changes introduced in Cycle 40 relative to the earlier Cycle 38 are described by HIRLAM Consortium (2016).

Here, we have set up a $3-\mathrm{km}$ horizontal resolution domain that covers the Norwegian Sea, the North Sea, the Barents Sea, and the Baltic Sea $(900 \times 1500$ grid points, see Fig. 1$)$. The model runs on a Lambert conformal conic grid with its central meridian at $42^{\circ} \mathrm{W}$. The latitude of its projection origin and standard parallel is $66.3^{\circ} \mathrm{N}$. The use of $3-\mathrm{km}$ grid resolution is coarser than the AROME-based operational models, which typically run at $2.5-\mathrm{km}$-or-higher resolution. The $3-\mathrm{km}$ Norwegian Reanalysis (NORA3) grid could be on the limit for which deep convection should be partly parameterized as a subgrid process in addition to the permitted deep convection. Too-low resolution could potentially cause unrealistic precipitation (Deng and Stauffer 2006). An upper resolution limit of $2.5 \mathrm{~km}$ has been recommended by several studies (Gerard et al. 2009; Malardel 2013; Yano et al. 2018). Here we have chosen $3 \mathrm{~km}$ as an affordable compromise that allows us to cover the entire Norwegian Sea. Although this is slightly coarser than what is commonly used, we find that the performance is comparable to that of the operational $2.5-\mathrm{km}$ model domain (see the appendix).

In NORA3, the HARMONIE-AROME runs have been organized as a sequence of short prognostic runs (see appendix Table A1 and Fig. A2). The nonhydrostatic fully compressible Euler equations are discretized by a semi-Lagrangian (SL) advection scheme without horizontal staggering. The stable extrapolation two-time-level scheme (SETTLS; see Hortal 2002) is applied to ensure stable integration. In the first time steps, a limit on the three-dimensional divergence is applied to avoid problems when initializing from a lower-resolution host model (Bengtsson et al. 2017).

\section{a. The nonhydrostatic model formulation}

The evolution equations use a terrain-following pressurebased vertical $\sigma$ coordinate (Simmons and Burridge 1981; Laprise 1992) on 65 levels (similar to the operational model; Müller et al. 2017b) with the lowest level at $12 \mathrm{~m}$ and the uppermost level at $10 \mathrm{hPa}$. The time step is $60 \mathrm{~s}$. The model comprises 12 three-dimensional prognostic variables; five hydrometeors (rain, snow, graupel, cloud droplets, and ice crystals), horizontal wind, temperature, specific water vapor content, and turbulent kinetic energy. In addition to these 10 prognostic variables are two nonhydrostatic variables related to pressure and vertical momentum (see Bénard et al. 2010).

\section{b. Surface analysis}

Surface fields are taken from the previous forecast of NORA3 but adjusted to applicable observations through a surface analysis that is a combination of Code d'Analyze Nécessaire á ARPEGE pour ses Rejets et son Initialization (CANARI; see Giard and Bazile 2000; Le Moigne et al. 2012; Taillefer 2002) and Surface Externalisée (SURFEX; Masson et al. 2013) (CANARI-OI-Main). In CANARI-OI-Main, the 

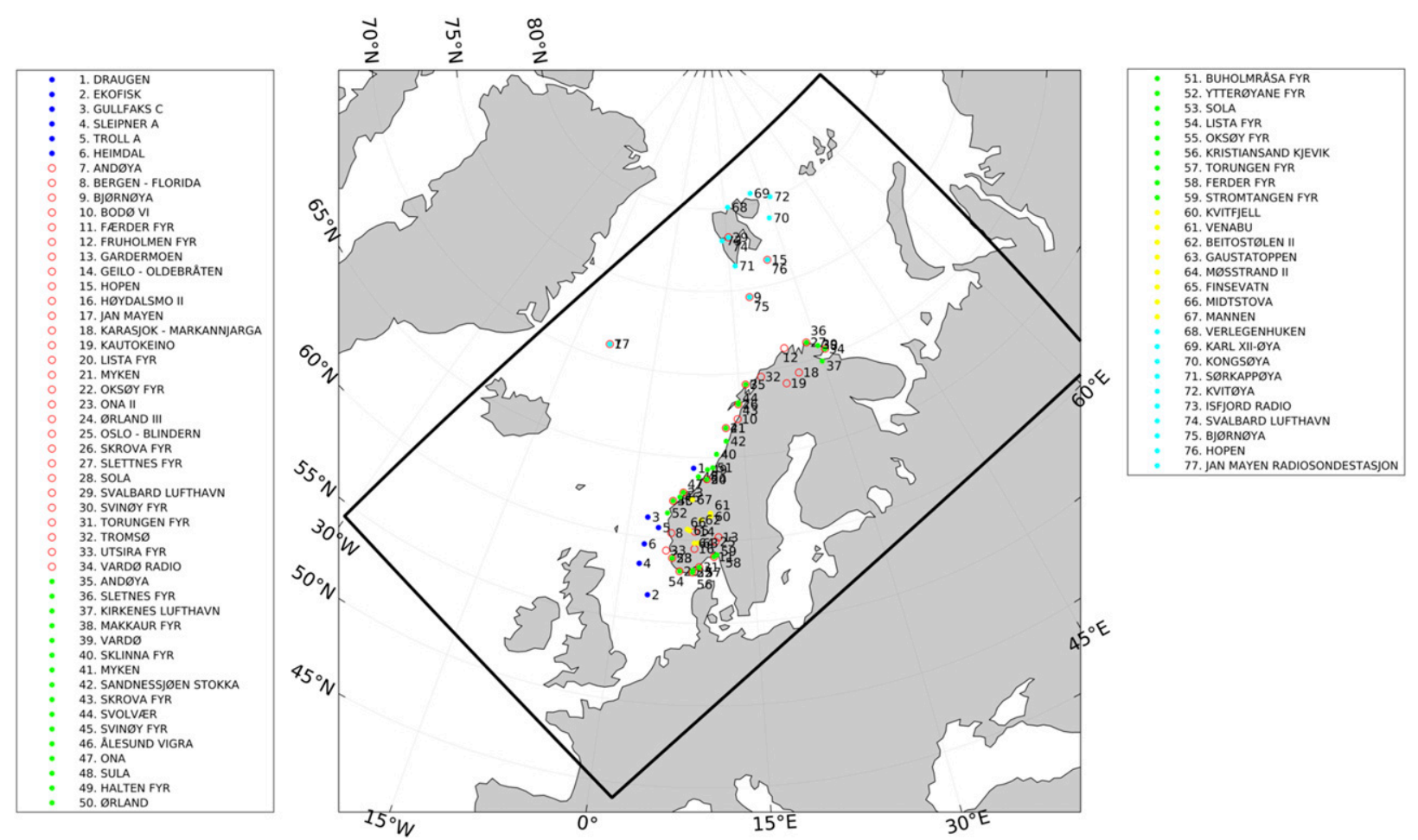

FIG. 1. Map showing the NORA3 domain and location of observation stations. Blue dots indicate maritime stations, red open circles are reference stations, green dots are coastal stations, yellow dots are mountain stations, and light-blue dots are Arctic stations.

analysis increment is calculated using an optimum interpolation method (Daley 1991). The method starts with a general initialization and continues with a quality control that selects pertinent observations before the analysis of the different fields is performed. The formulation of the optimum interpolation is

$$
\mathbf{x}_{a}=\mathbf{x}_{g}+\mathbf{P} \mathbf{H}^{\mathrm{T}}\left(\mathbf{O}+\mathbf{H} \mathbf{P} \mathbf{H}^{\mathrm{T}}\right)^{-1}\left(\mathbf{H x}_{g}-\mathbf{y}\right)
$$

Here, $\mathbf{x} \in R^{n}$ is the state vector of the atmosphere (all prognostic variables in all grid points $n), \mathbf{y} \in R^{m}$ is the observation vector of length $m, \mathbf{O} \in R^{m \times m}$ is the variance-covariance matrix of the observation errors (assumed to be diagonal), $\mathbf{P} \in$ $R^{n \times n}$ is the variance-covariance matrix of the model errors (first-guess errors), and $\mathbf{H}$ is the observation operator, which here is supposed to be linear (Taillefer 2002). Subscripts "a" and "g" denote analysis and first guess, respectively. Soil moisture and soil temperature are corrected in the Interactions between Soil, Biosphere, and Atmosphere (ISBA) land surface model running within the surface module (SURFEX; see below) using the updated information from the screen-level observation output from CANARI.

\section{c. Physical parameterizations}

HARMONIE-AROME uses microphysics that is a threeclass ice parameterization of cloud ice, snow, and a combination of graupel and hail (ICE3; Pinty and Jabouille 1998; Lascaux et al. 2006). The microphysics also comprises water vapor, cloud liquid water, and rain. The microphysics runs with the option "OCND2," which improves clouds in cold conditions (Müller et al. 2017b). Raindrop activation is parameterized by the Kogan autoconversion (Khairoutdinov and Kogan 2000). Shallow convection is parameterized in the eddy diffusivity mass flux (EDMF-M) scheme (Siebesma et al. 2003, 2007; de Rooy and Siebesma 2008, 2010). Turbulence is represented in the HARMONIE with RACMO Turbulence (HARATU) parameterization (van Meijgaard et al. 2012; Lenderink and Holtslag 2004). HARATU uses a prognostic equation for the turbulent kinetic energy combined with a diagnostic length scale. HARATU distinguishes between stable condition and near-neutral to convective conditions. For radiation, the Rapid Radiative Transfer Model (RRTM) (Mlawer et al. 1997) is used for longwave radiation, while shortwave runs the ECMWF operational shortwave (SW) scheme (ECMWF 1989). Aerosols and ozone are based on monthly climatologies.

\section{d. Land and ocean surface processes}

The land and ocean surface module used in HARMONIEAROME is the comprehensive SURFEX model (Masson et al. 2013), consisting of four different models that represent nature, lakes and rivers, urban regions, and sea as different tiles. Exchanges of meteorological and radiative fields connect the atmospheric model and the SURFEX model. Each surface grid cell receives basic atmospheric fields, the air temperature, specific humidity, the horizontal wind components, pressure, total precipitation, and longwave radiation as well as the shortwave direct and diffuse radiation. SURFEX then computes the averaged fluxes for momentum and sensible and 


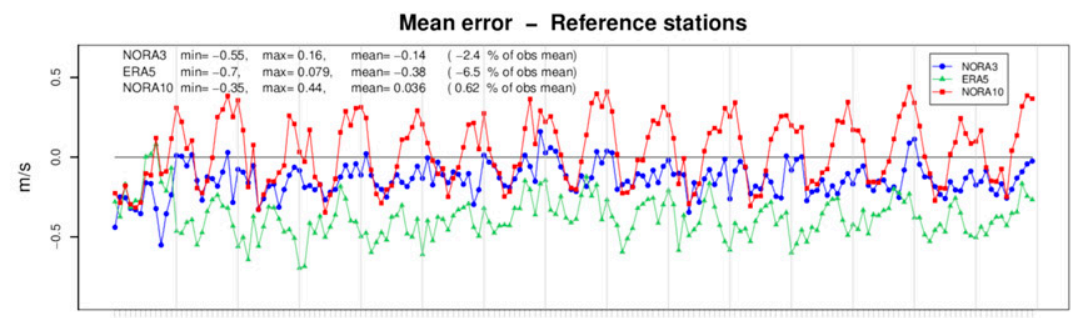

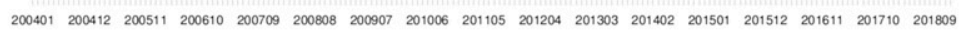

Date

(a)

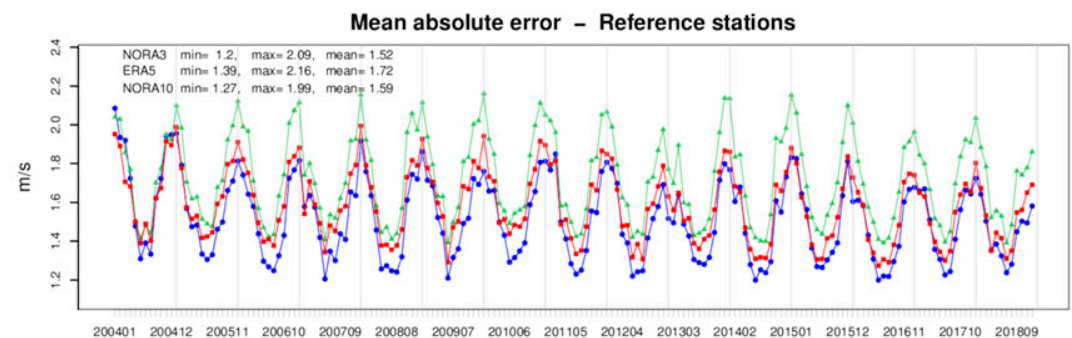

Date

(b)

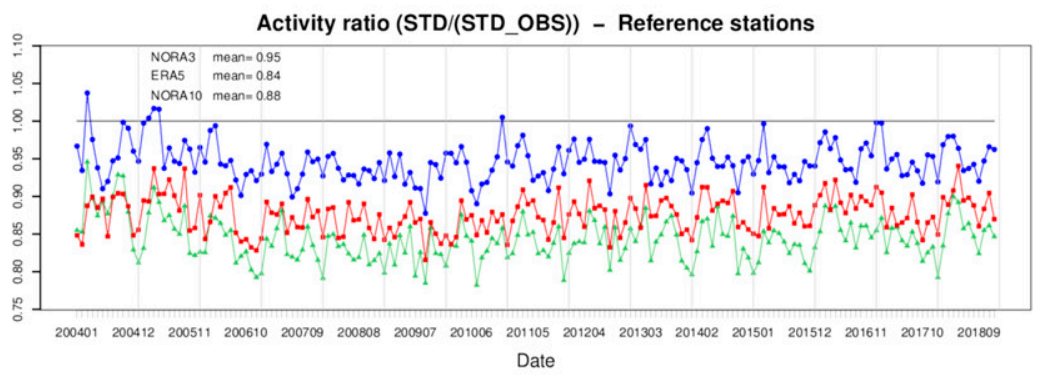

(c)

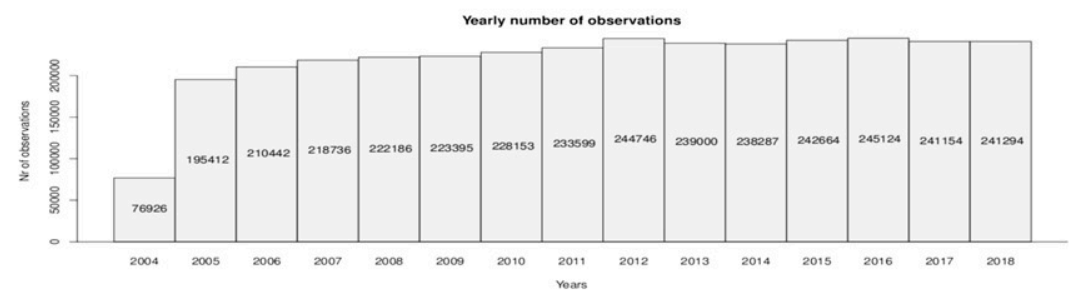

(d)

FIG. 2. Time series of NORA3 (blue), NORA10 (red), and ERA5 (green) (a) mean error, (b) MAE, and (c) the AR. (d) The yearly number of observations used in the validation. All statistics were computed for the period 2004-18.

latent heat that serve as lower boundary conditions for the atmospheric radiation and turbulent schemes (Le Moigne et al. 2012).

The sea surface and the atmosphere are connected through the Unified Multicampaigns Estimates (ECUME) scheme (Weill et al. 2003; Belamari 2005; Belamari and Pirani 2007). ECUME is a bulk parameterization scheme with neutral transfer coefficients at $10 \mathrm{~m}$ estimated from a multicampaign calibration derived from the AUTOFLUX Linked Base for Atmospheric Transfer at the Ocean Surface (ALBATROS) database, which collected data from different flux measurement campaigns (Weill et al. 2003). Sea surface roughness is parameterized as (Smith 1988)

$$
z_{0}=\frac{\alpha u_{*}^{2}}{g}+\frac{\beta \nu}{u_{*}},
$$


TABLE 1. Reference stations' 10-m wind speed statistics (2004-18). The best performance (in comparison with the observed 10-m wind speed) is marked in boldface type.

\begin{tabular}{|c|c|c|c|c|c|c|c|c|c|c|c|c|}
\hline & Jan & Feb & Mar & Apr & May & Jun & Jul & Aug & Sep & Oct & Nov & Dec \\
\hline & \multicolumn{12}{|c|}{ Monthly mean values } \\
\hline Obs $\left(\mathrm{m} \mathrm{s}^{-1}\right)$ & 6.84 & 6.43 & 6.23 & 5.54 & 5.24 & 5.03 & 4.71 & 4.71 & 5.54 & 6.08 & 6.49 & 6.73 \\
\hline NORA3 $\left(\mathrm{m} \mathrm{s}^{-1}\right)$ & 6.76 & 6.38 & 6.13 & 5.40 & 5.03 & 4.82 & 4.53 & 4.56 & 5.38 & 5.92 & 6.36 & 6.67 \\
\hline $\operatorname{ERA} 5\left(\mathrm{~m} \mathrm{~s}^{-1}\right)$ & 6.40 & 6.00 & 5.76 & 5.10 & 4.79 & 4.59 & 4.35 & 4.41 & 5.30 & 5.78 & 6.11 & 6.34 \\
\hline \multirow[t]{2}{*}{ NORA10 $\left(\mathrm{m} \mathrm{s}^{-1}\right)$} & 7.07 & 6.60 & 6.24 & 5.44 & 5.02 & 4.82 & 4.56 & 4.67 & 5.65 & 6.31 & 6.72 & 7.00 \\
\hline & \multicolumn{12}{|c|}{ Deviation from obs } \\
\hline NORA3 (\%) & -1.2 & -0.8 & -1.5 & -2.4 & -3.9 & -4.1 & -3.8 & -3.2 & -2.9 & -2.6 & -2.0 & -0.8 \\
\hline ERA5 (\%) & -6.4 & -6.8 & -7.5 & -8.0 & -8.5 & -8.7 & -7.7 & -6.5 & -4.4 & -4.9 & -5.7 & -5.7 \\
\hline NORA10 (\%) & 3.3 & 2.6 & 0.2 & -1.8 & -4.1 & -4.2 & -3.3 & -0.9 & 2.1 & 3.7 & 3.7 & 4.0 \\
\hline
\end{tabular}

where $\alpha$ is the Charnock constant (here $\alpha$ is assumed to take the value 0.011; see Charnock 1955). Furthermore, $\beta$ is a numerical constant, $g$ is the gravitational acceleration, and $\nu$ is the kinematic viscosity coefficient. The ECUME scheme is summarized in appendix Table A2.

Surface types are extracted from the ECOCLIMAP2 database (Faroux et al. 2013). ECOCLIMAP2 is a 1-km-resolution database based on satellite information. Surface topography is defined by Global Multi-Resolution Terrain Elevation Data 2010 (GMTED2010; Danielson and Gesch 2011).

\section{e. Forcing data}

ERA5 (Hersbach et al. 2020) is the newest reanalysis from ECMWF. It is produced as part of the Copernicus Climate Change Service (C3S). ERA5 is based on the Integrated Forecasting System (IFS) Cy41r2. The horizontal resolution of (a)
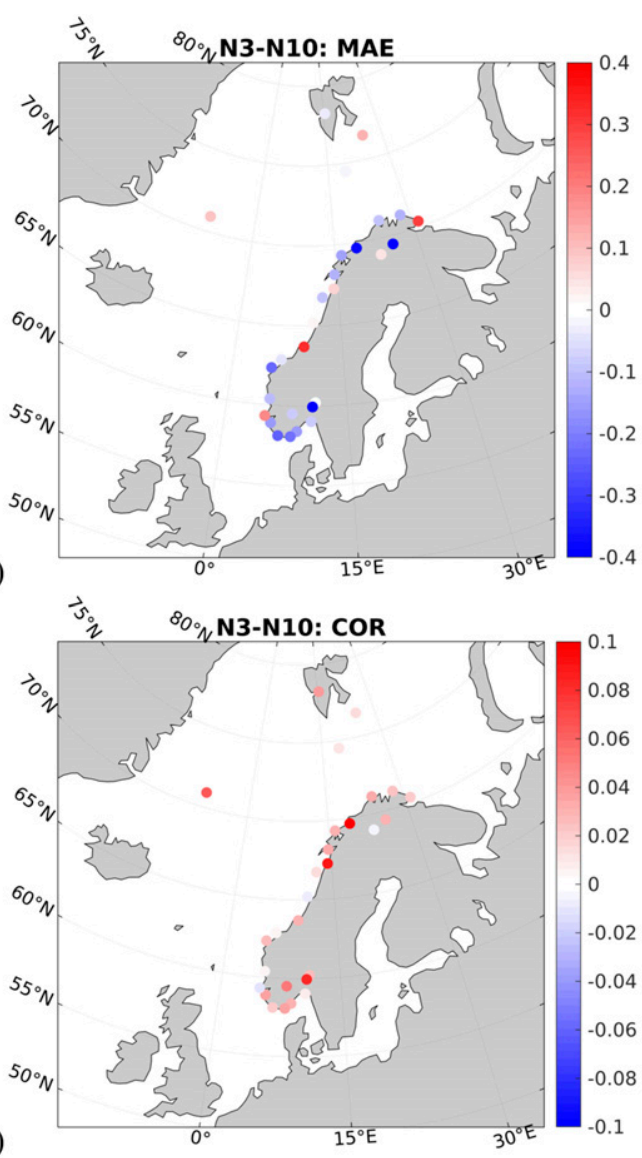

(b)
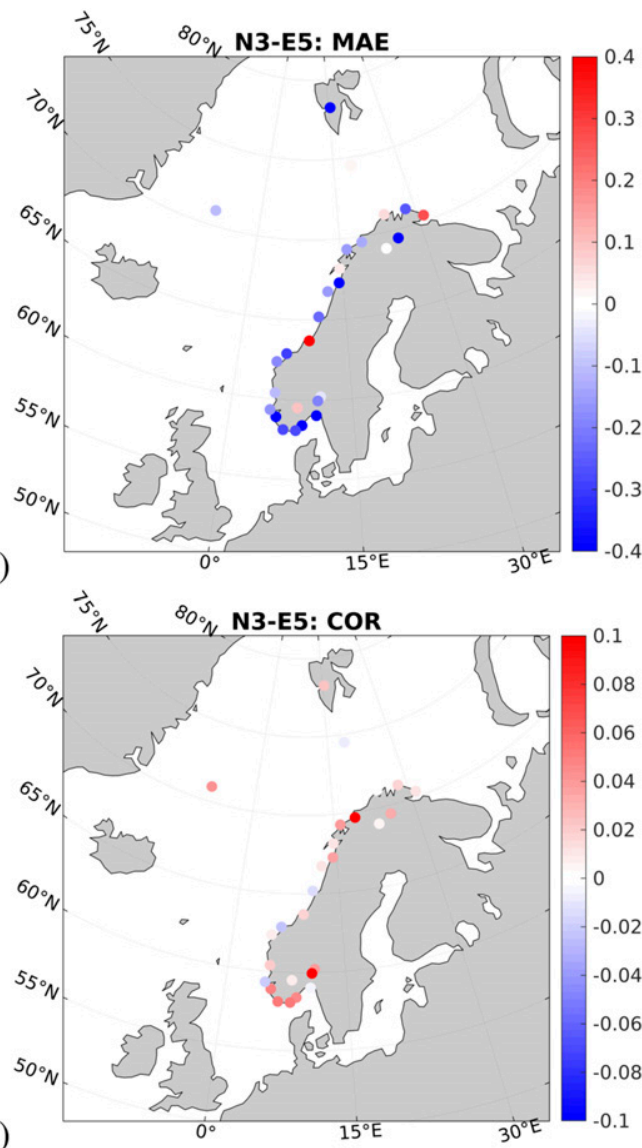

FIG. 3. Difference [(a) NORA3 - NORA10; (b) NORA3 - ERA5] of MAEs on reference stations (blue when NORA3 has lower MAE). Also shown is a comparison of Pearson's correlation coefficient (red when NORA3 scores higher): (c) NORA3 - NORA10; (d) NORA3 - ERA5. All statistics were computed for the period 2004-18. 


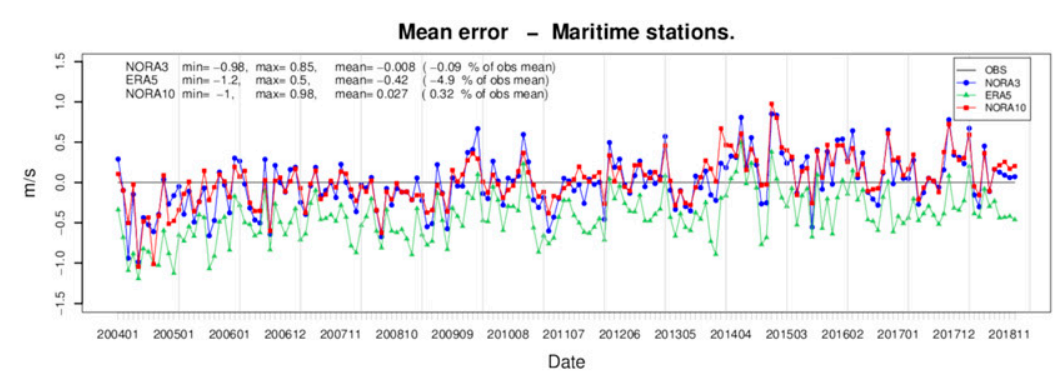

(a)

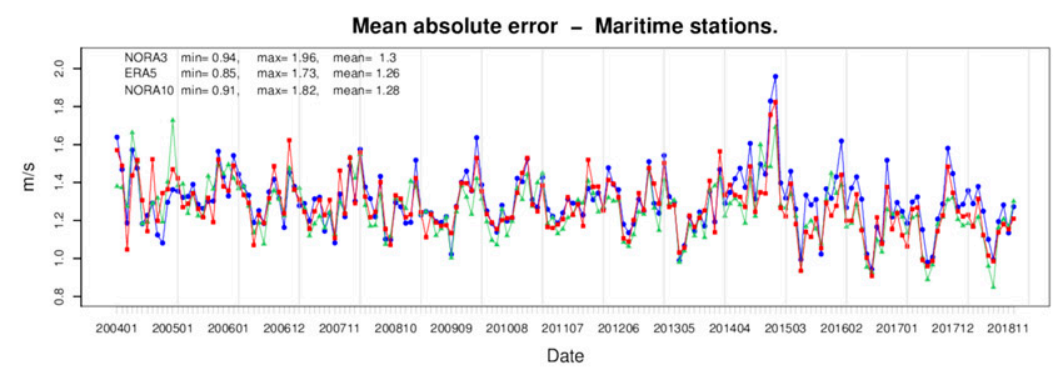

(b)

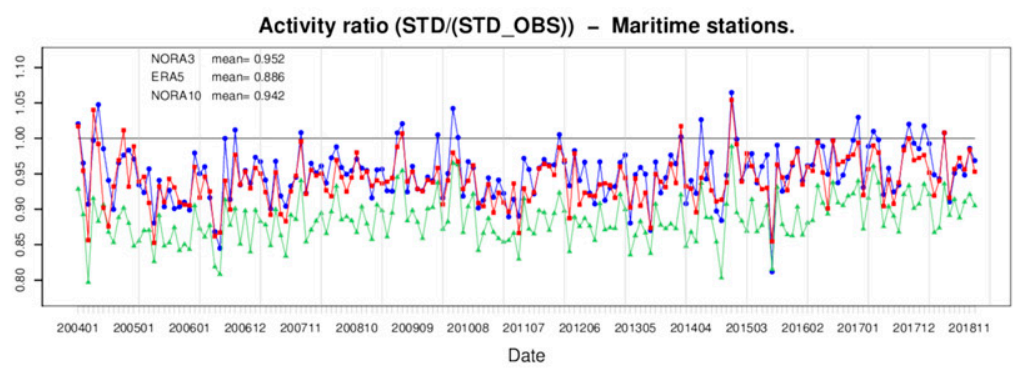

(c)

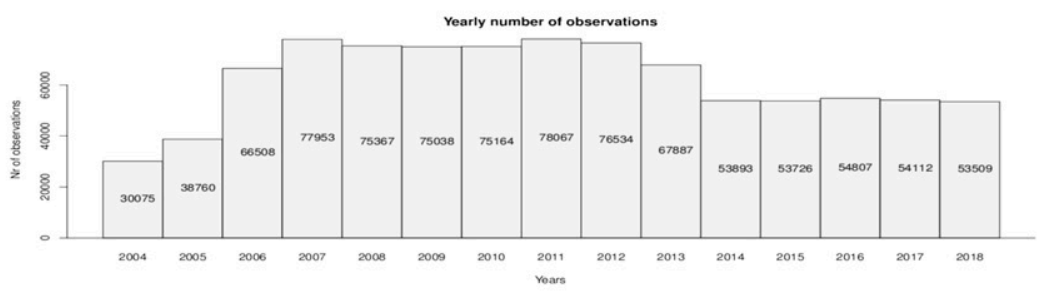

(d)

FIG. 4. As in Fig. 2, but for the maritime stations.

ERA5 is $31 \mathrm{~km}$. ERA5 has been shown (Hersbach et al. 2020) to provide considerably better wind, temperature, humidity, and precipitation fields than the earlier, coarser $(79 \mathrm{~km})$, ERAInterim reanalysis (Dee et al. 2011). Its performance over the open ocean is generally considered to be very good (Rivas and Stoffelen 2019). Renfrew et al. (2021) also note that ERA5 performs well in terms of wind and turbulent fluxes over the open ocean but found that its performance in the marginal ice zone is significantly poorer. They attributed the difference in quality to excessively smooth sea ice distribution in the surface boundary conditions.
Here we start each prognostic run from an initialized model state built from an analyzed surface field and a simple upper-air blending with ERA5 fields. Upper-air temperature, specific humidity, and the zonal and meridional wind components are taken from ERA5 and interpolated to the high-resolution grid. The remaining upper-air prognostic variables are taken from the first guess, that is, the last forecast valid at the start of the new forecast (see Fig. A3). Observations used by the surface analysis are all land and sea surface measurements retrieved from ECMWF's Meteorological Archival and Retrieval System (MARS). 
TABLE 2. Maritime stations' 10-m wind speed statistics (2004-18). The best performance (in comparison with the observed 10-m wind speed) is marked in boldface type.

\begin{tabular}{|c|c|c|c|c|c|c|c|c|c|c|c|c|}
\hline & Jan & Feb & Mar & Apr & May & Jun & Jul & Aug & Sep & Oct & Nov & Dec \\
\hline & \multicolumn{12}{|c|}{ Monthly mean values } \\
\hline $\operatorname{Obs}\left(\mathrm{m} \mathrm{s}^{-1}\right)$ & 10.82 & 9.81 & 8.98 & 7.81 & 7.28 & 6.66 & 6.80 & 7.08 & 8.56 & 9.50 & 9.98 & 10.24 \\
\hline NORA3 $\left(\mathrm{m} \mathrm{s}^{-1}\right)$ & 10.91 & 9.94 & 9.03 & 7.76 & 7.15 & 6.71 & 6.64 & 6.98 & 8.48 & 9.49 & 10.10 & 10.35 \\
\hline $\operatorname{ERA} 5\left(\mathrm{~m} \mathrm{~s}^{-1}\right)$ & 10.31 & 9.45 & 8.59 & 7.42 & 6.88 & 6.41 & 6.38 & 6.69 & 8.11 & 9.04 & 9.61 & 9.81 \\
\hline \multirow[t]{2}{*}{ NORA10 $\left(\mathrm{m} \mathrm{s}^{-1}\right)$} & 10.93 & 9.95 & 9.08 & 7.82 & 7.18 & 6.66 & 6.64 & 6.98 & 8.54 & 9.59 & 10.15 & 10.40 \\
\hline & \multicolumn{12}{|c|}{ Deviation from obs } \\
\hline NORA3 (\%) & 0.8 & 1.3 & 0.5 & -0.7 & -1.8 & 0.9 & -2.3 & -1.3 & -0.9 & -0.1 & 1.3 & 1.1 \\
\hline ERA5 (\%) & -4.8 & -3.7 & -4.4 & -4.9 & -5.5 & -3.8 & -6.2 & -5.5 & -5.3 & -4.8 & -3.7 & -4.2 \\
\hline NORA10 (\%) & 0.95 & 1.4 & 1.1 & 0.1 & -1.4 & 0.1 & -2.3 & -1.3 & -0.3 & 1.0 & 1.7 & 1.6 \\
\hline
\end{tabular}

\section{Results}

\section{a. General performance of NORA3}

The surface wind speed of NORA 3 is compared with a range of quality-assured offshore (maritime) and land-based observing

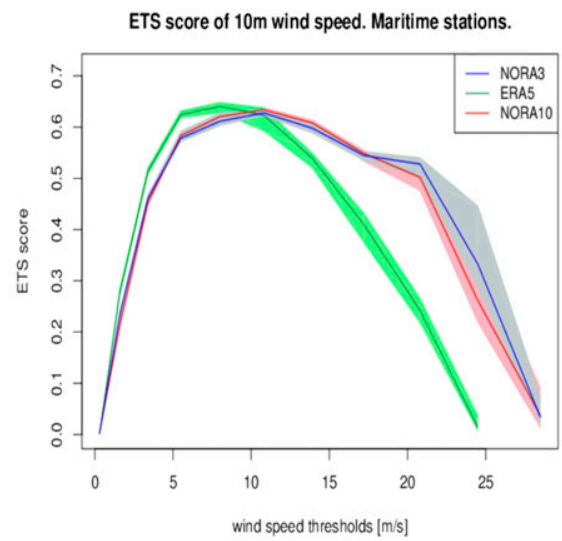

(a)

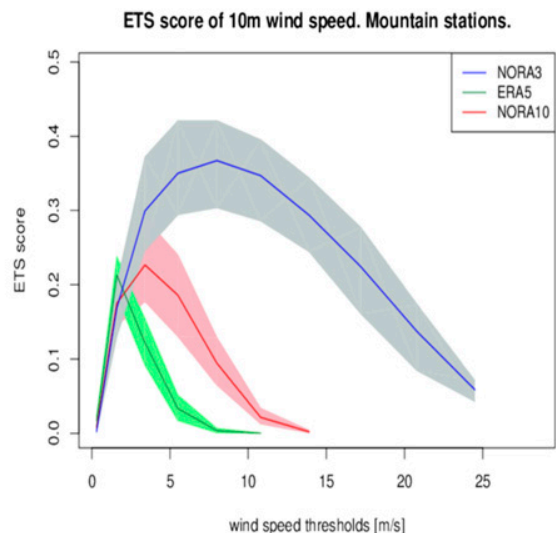

(c)

FIG. 5. ETS for (a) maritime, (b) coastal, (c) mountain, and (d) Arctic stations. Statistics were computed for the period 2004-18 for the three first categories and for 2010-18 for the Arctic stations. All panels include 95\% confidence limits based on a nonparametric bootstrap procedure.

stations retrieved from the Norwegian Meteorological Institute (https://www.met.no/en and https://frost.met.no/index.html).

A comparison with the earlier $10-\mathrm{km}$ Norwegian Hindcast Archive (NORA10; see Reistad et al. 2011; Furevik and Haakenstad 2012) and the host analysis ERA5

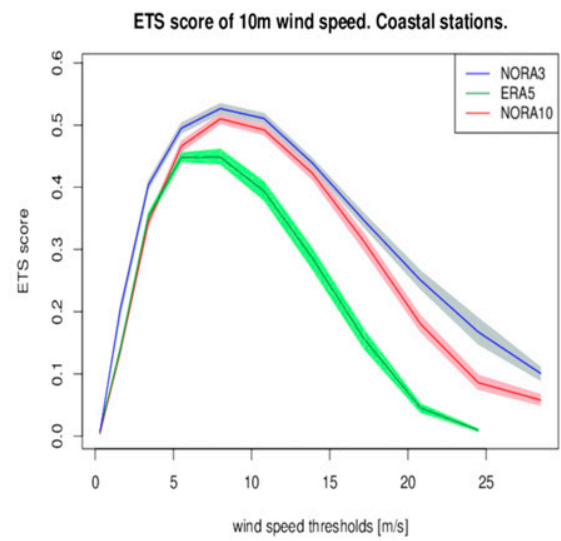

(b)

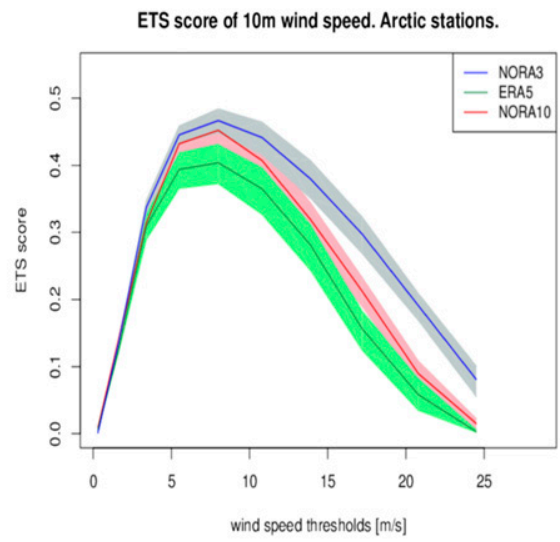

(d) 
(Hersbach et al. 2020) is also performed. We have excluded observations from locations where the model topography differs by more than $200 \mathrm{~m}$ from the actual station height in either of the three datasets. The observation stations that are used are shown in Fig. 1.

Three statistical measures are used repeatedly in the following: (i) the mean error (or bias), (ii) the mean absolute error (MAE; see Wilks 2006, 279-281), and (iii) the model activity ratio (AR). The latter is the ratio of the modeled standard deviation (std) over the observed standard deviation of the $10-\mathrm{m}$ wind speed and is a convenient way to compare the variability of observed and modeled quantities:

$$
\operatorname{AR}=\frac{\operatorname{std} U_{m}}{\operatorname{std} U_{o}} .
$$

In addition to the validation metrics listed above, we use Pearson's correlation coefficient (Press et al. 2007, 745-747) and the equitable threat score (ETS). The latter is otherwise known as the Gilbert skill score (Gandin and Murphy 1992; Wilks 2006). The ETS is a categorical score; that is, it classifies a hit or miss, determined by a threshold value, in our case the values of the wind speed. It is defined as

$$
\mathrm{ETS}=\frac{a-a_{r}}{a+b+c-a_{r}}
$$

where $a$ is the number of observed events that are correctly forecast (hits), $b$ is the number of forecast events for which the event was not observed (false alarms), $c$ is the number of events observed but not forecast (misses), and $d$ is the number of events that were not observed and (correctly) not forecast (correct negatives). The number of hits due to random forecasts is

$$
a_{r}=(a+b)(a+c) / n
$$

Here, $n=a+b+c+d$ is the total potential number of events, whether or not they occurred (were observed). The ETS has a range from $-1 / 3$ to 1 , where 1 is a perfect score and 0 denotes no skill (Wilks 2006). The score is sensitive to the climatological probabilities of the events, making it useful also in rare-event situations.

\section{1) VAlidation AgAinst REFERENCE STATIONS}

The reference validation uses hourly measurements from a set of quality-assured stations shown in Fig. 1 (marked with red open circles) and described in Table A3 denoted with category reference station (RS). The reference stations are found in one or more of the following databases: the Regional Basic Synoptic Network (RBSN), Regional Basic Climatological Network (RBCN), Reference Climatological Station (RCS), and Global Climate Observing System Surface Network (GSN). The stations consist mostly of land-based observations from the Norwegian mainland and Spitsbergen as well as Bear Island, Jan Mayen Island, and Hopen Island. The comparison between the model results and the observations is handled by bilinear interpolation of the model results to the observation positions. Although the stations are quality assured, some measurements can be spurious. Therefore, all observations

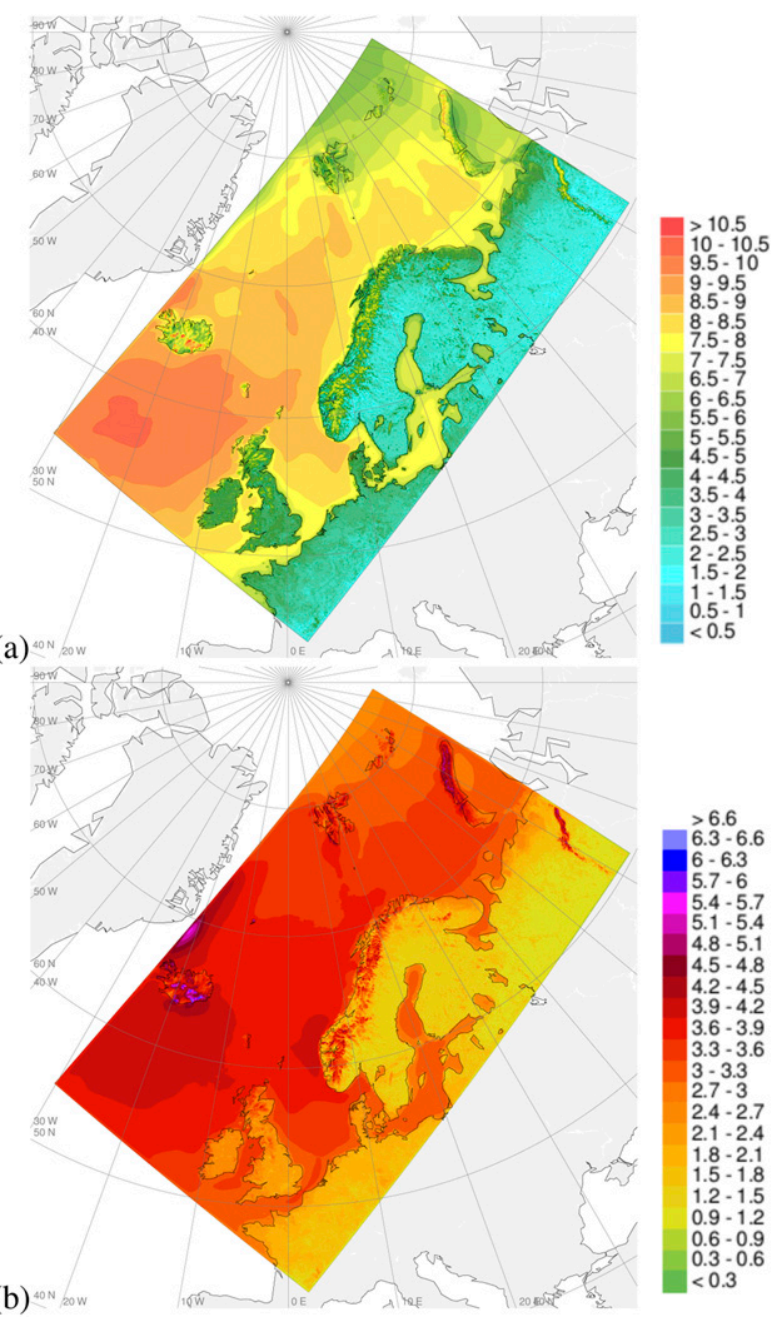

FIG. 6. The NORA3 10-m wind speed $\left(\mathrm{m} \mathrm{s}^{-1}\right)$ (a) average and (b) standard deviation for the period 2004-18.

deviating by more than $20 \mathrm{~m} \mathrm{~s}^{-1}$ from the model results are rejected from the validation.

The time series of $10-\mathrm{m}$ wind speed bias, mean absolute error, and activity ratio of all three datasets (NORA3, NORA10, and ERA5) are shown for the period 2004-18 in Fig. 2 (observation count is shown in Fig. 2d). There is a marked reduction in the annual cycle of the mean wind error (bias) in NORA3 (blue) when compared with NORA10 (red), with considerably less overestimation of the wind speed during fall [September- January (SON)] and winter [DecemberFebruary (DJF)] and less underestimation during spring [March-May (MAM)] and summer [June-August (JJA)] (see also Table 1 for monthly mean values).

A negative year-round bias in ERA5 (green) of about $-0.38 \mathrm{~m} \mathrm{~s}^{-1}$ is found. The activity ratio of NORA3 is significantly better than both NORA10 and ERA5. An overview of the performance of NORA3 in terms of MAE and correlation on the reference stations is given in Fig. 3. The MAE is mostly lower than NORA10 (Fig. 3a). The improvement over ERA5 (Fig. 3b) is somewhat stronger, although in both cases there are 


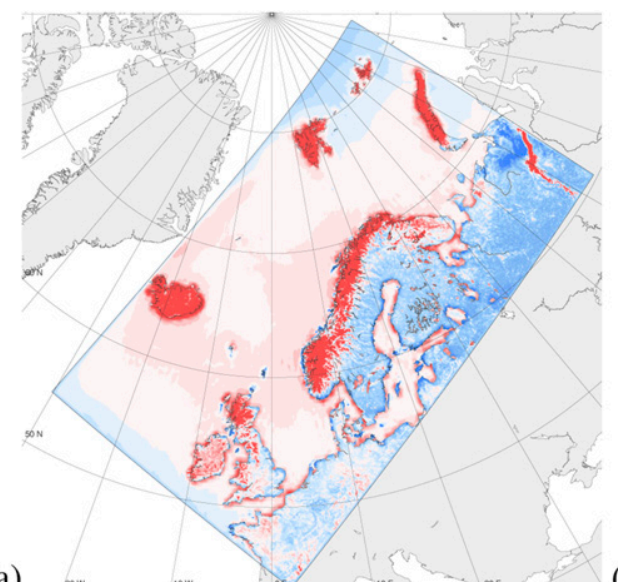

(a)

(c) sow

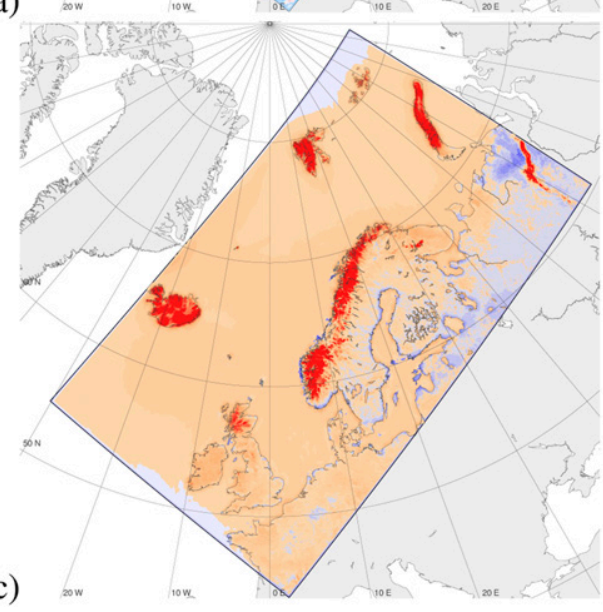

(b)
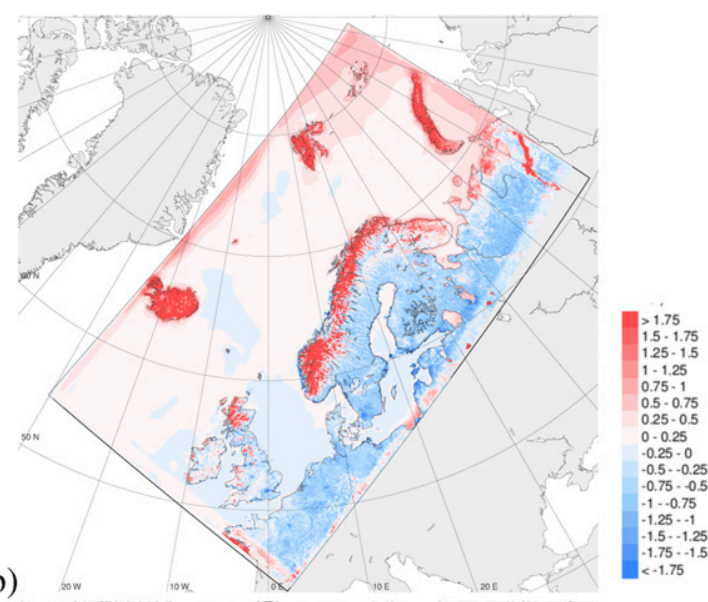

(d)

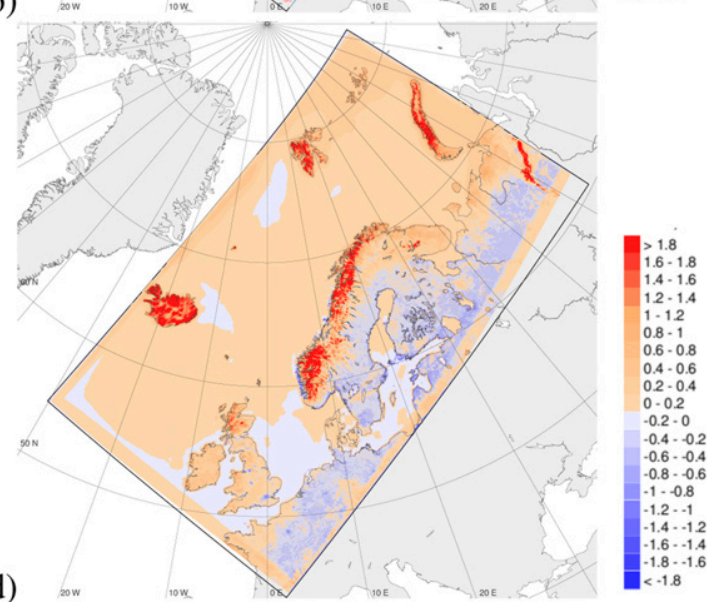

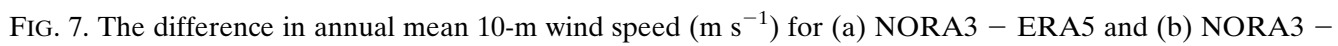
NORA10. Also shown is the difference in 10-m wind speed standard deviation (c) NORA3 - ERA5 and (d) NORA3 - NORA10. All panels show statistics for the period 2004-18.

exceptions. The correlation (lower panels) is also generally higher, and again the improvement over ERA5 (Fig. 3d) is stronger than over NORA10 (Fig. 3c). This is unsurprising, as the stations that make up the reference list are in most cases located in complex terrain, which is not well resolved by ERA5.

\section{2) VALIDATION AGAINST MARITIME STATIONS}

We have chosen a subset of offshore stations [see Fig. 1 (marked with blue dots) and the category maritime station (MR) in Table A3] that have nearly continuous measurements during the validation period, 2004-18, and where accurate information about the sensor height is available. The stations are located in the North Sea and the Norwegian Sea between $56.54^{\circ} \mathrm{N}$ and $64.35^{\circ} \mathrm{N}$ (marked with dark blue dots in Fig. 1) and cover a central part of the maritime NORA3 domain. The stations measure wind speed at heights between 71 and $141 \mathrm{~m}$. The wind observations are reduced to 10-m height following the NORSOK wind profile (NORSOK 2007; Andersen and Løvseth 2006; Haakenstad et al. 2020). NORSOK is in common use in the Norwegian offshore community and was chosen based on a comparison of four different wind profiles (not shown) using high-quality wind speed measurements at different heights from the German FINO1 offshore platform, located in the southern North Sea (at $\left.54.015^{\circ} \mathrm{N}, 6.604^{\circ} \mathrm{E}\right)$. For brevity, the $10-\mathrm{m}$ values will hereinafter be referred to as the observed values.

Figure 4a shows the monthly values of mean error in 10-m wind speed for NORA3, ERA5 and NORA10 (observation count is shown in Fig. 4d). NORA3 has a negligible long-term average mean error. However, it varies from mainly negative values in the start of the period to more positive values in the end of the period 2004-18. For the period with the best observation coverage (2006-13), NORA3 has an average mean

TABLE 3. Percentiles of $10-\mathrm{m}$ wind speed for maritime stations (2004-18). The best performance (in comparison with the observed $10-\mathrm{m}$ wind speed) is marked in boldface type.

\begin{tabular}{lccccccc}
\hline \hline & 50 & 75 & 90 & 95 & 98 & 99 & Max value \\
\hline Obs & 8.22 & 11.59 & 14.79 & 16.69 & 18.86 & 20.38 & 28.76 \\
NORA3 & $\mathbf{8 . 2 4}$ & $\mathbf{1 1 . 4 8}$ & 14.53 & 16.35 & 18.51 & $\mathbf{2 0 . 0 1}$ & $\mathbf{2 8 . 8 0}$ \\
ERA5 & 7.87 & 10.90 & 13.78 & 15.45 & 17.26 & 18.44 & 24.71 \\
NORA10 & 8.24 & 11.47 & $\mathbf{1 4 . 6 0}$ & $\mathbf{1 6 . 4 8}$ & $\mathbf{1 8 . 5 6}$ & 19.98 & 27.48 \\
\hline
\end{tabular}




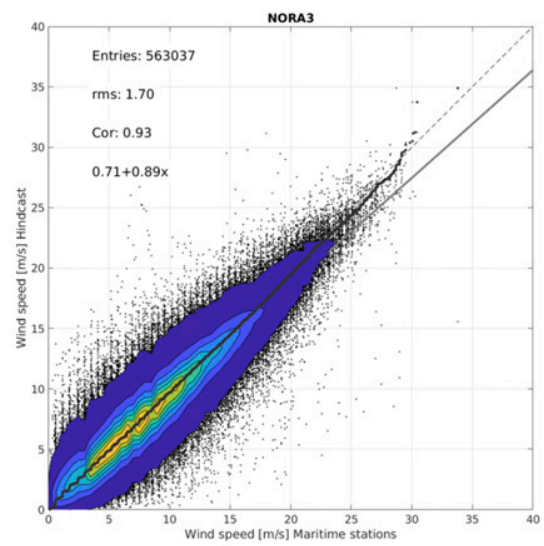

(a)

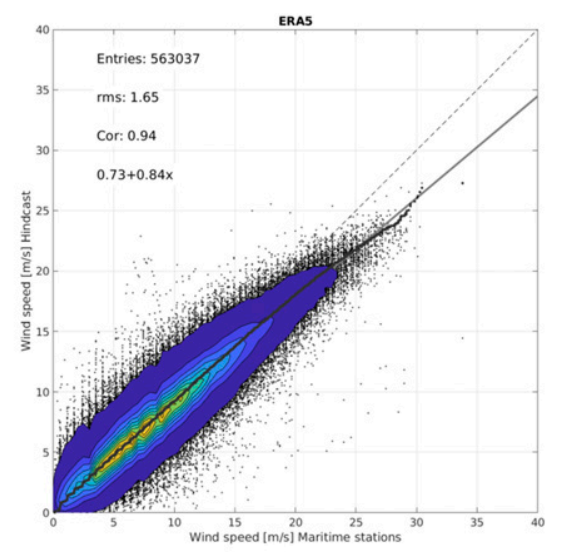

(b)

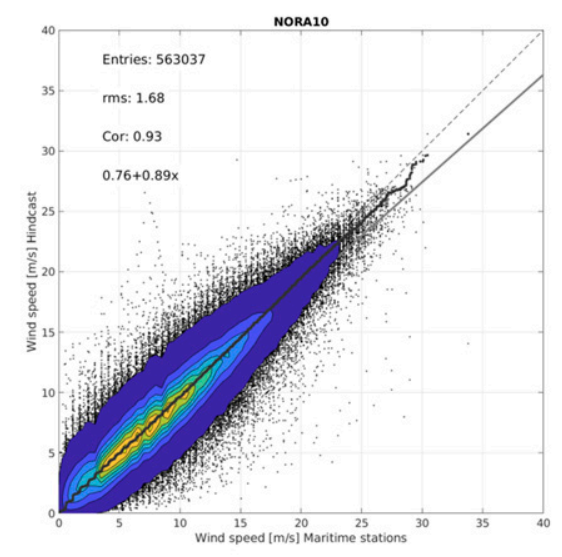

(c)

FIG. 8. Combined scatter and Q-Q plots of (a) NORA3, (b) ERA5, and (c) NORA10 vs maritime wind observations (period 2004-18).

error of $-0.06 \mathrm{~m} \mathrm{~s}^{-1}$, as compared with -0.04 and $-0.45 \mathrm{~m} \mathrm{~s}^{-1}$ for NORA10 and ERA5, respectively. In the same period, the mean absolute error is $1.29 \mathrm{~m} \mathrm{~s}^{-1}$ for NORA3 and NORA10 and $1.26 \mathrm{~m} \mathrm{~s}^{-1}$ for ERA5 (see Fig. 4b). Figure 4c shows that NORA3 has a slightly better activity ratio than NORA10 and significantly better activity ratio than ERA5.

Table 2 summarizes the monthly mean values of the observations, NORA3, ERA5, and NORA10 and the relative differences of the model values in comparison with the observations. The relative differences become more sensitive during summertime and all the model values show a maximum relative underestimation in July. ERA5 shows the greatest underestimation of $-6.2 \%$ while the value is $-2.3 \%$ for NORA3 and NORA10. NORA3 shows a maximum overestimation of
$1.3 \%$ in November and February, and ERA5 underestimates the wind speed throughout the year.

\section{3) Categorical validation}

Figure 5 shows the ETS performance of NORA3, ERA5, and NORA10 for four different station classes: maritime, coastal, mountain, and Arctic stations. The stations are shown by, respectively, blue, green, yellow, and turquoise dots in Fig. 1. (All of the stations are also listed in Table A3.) For the Arctic stations, the instruments were upgraded in the period 2010-15; therefore, the years 2004-09 have been excluded from the Arctic ETS validation. The other station categories operate with the period 2004-18. All ETS estimates are shown with $90 \%$ confidence limits taken from 1000 nonparametric bootstrap estimates of the ETS. 


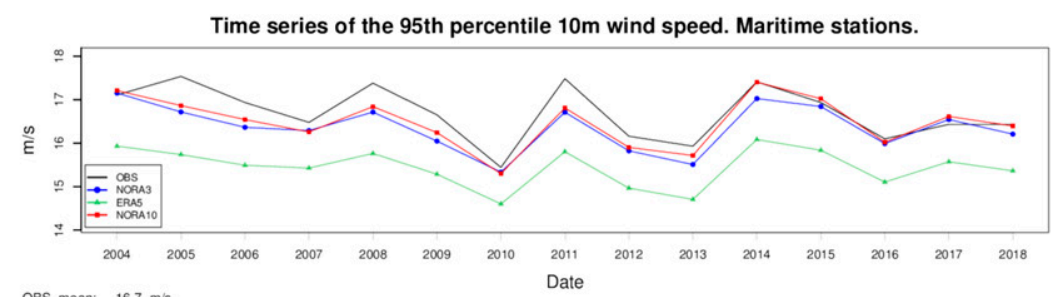

$\begin{array}{ll}\text { OBS mean: } & 16.7 \mathrm{~m} / \mathrm{s} \\ \text { N3 } 3 \text { mean: } & 16.4 \mathrm{~m} / \mathrm{s} \\ \text { E5 mean: } & 15.4 \mathrm{~m} / \mathrm{s} \\ \text { N10 mean: } & 16.5 \mathrm{~m} / \mathrm{s}\end{array}$

(a)

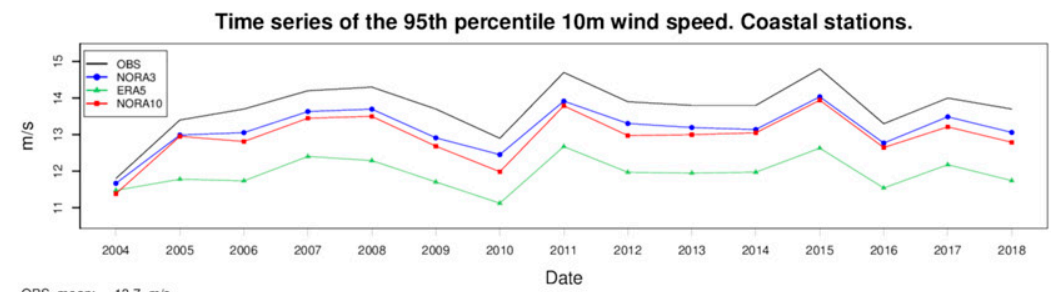

$\begin{array}{ll}\text { OBS mean: } & 13.7 \mathrm{~m} / \mathrm{s} \\ \text { N3 mean: } & 13.2 \mathrm{~m} / \mathrm{s} \\ \text { E5 mean: } & 11.9 \mathrm{~m} / \mathrm{s} \\ \text { N10 mean: } & 12.9 \mathrm{~m} / \mathrm{s}\end{array}$

(b)

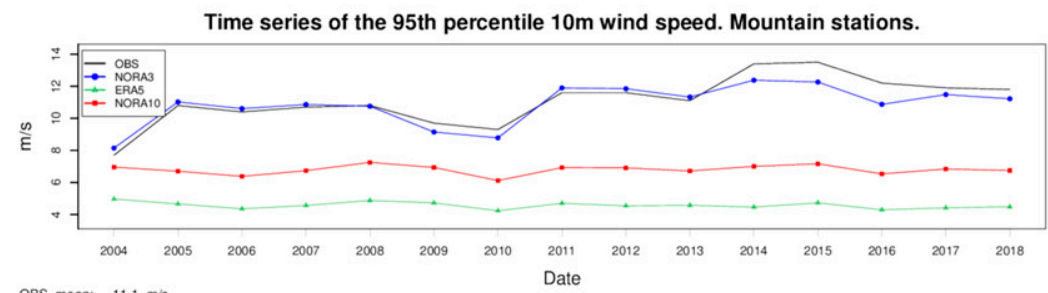

$\begin{array}{ll}\text { OBS mean: } & 11.1 \mathrm{~m} / \mathrm{s} \\ \text { N3 mean: } & 10.8 \mathrm{~m} / \mathrm{s} \\ \text { E5 mean: } & 4.57 \mathrm{~m} / \mathrm{s} \\ \text { N10 mean: } & 6.79 \mathrm{~m} / \mathrm{s}\end{array}$

(c)

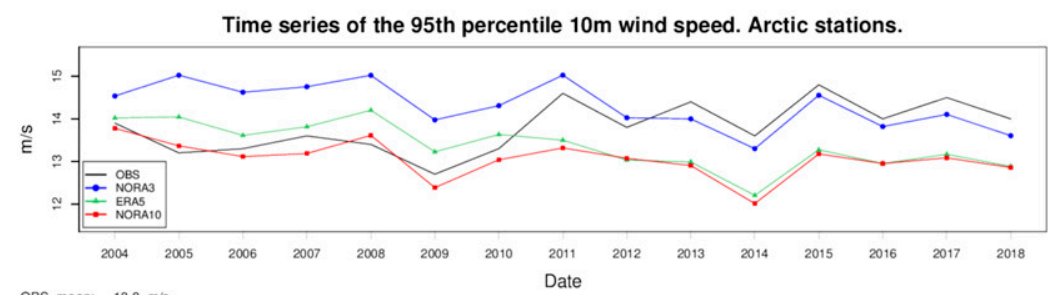

$\begin{array}{ll}\text { OBS mean: } & 13.8 \mathrm{~m} / \mathrm{s} \\ \text { N3 } 3 \text { mean: } & 14.3 \mathrm{~m} / \mathrm{s} \\ \text { E5 mean: } & 13.4 \mathrm{~m} / \mathrm{s} \\ \text { N10 mean: } & 13.1 \mathrm{~m} / \mathrm{s}\end{array}$

(d)

FIG. 9. Time series of the 95th-percentile 10-m wind speed for (a) maritime, (b) coastal, (c) mountain, and (d) Arctic stations. Observations are in black, NORA3 is in blue, ERA5 is in green, and NORA10 is in red. The mean value of the 95th percentile for the whole time period (2004-18) is shown at the lower left of the panels.

The best ETS is found for maritime stations with a maximum score of 0.64 by ERA5 for the wind speed category $8 \mathrm{~m} \mathrm{~s}^{-1}$ (fresh breeze). NORA3 has an ETS of 0.61 for this threshold but surpasses ERA5 for higher wind speed thresholds and has a score of 0.63 for strong breeze, $10.8 \mathrm{~m} \mathrm{~s}^{-1}$, which is identical to the NORA10 ETS. NORA10 and NORA3 have almost the same performance up to gale force $\left(17.2 \mathrm{~m} \mathrm{~s}^{-1}\right)$. Above that, NORA3 performs better. At the coastal stations (Fig. 5b), NORA3 outperforms ERA5 and NORA10 for all categories of wind speeds. At mountain stations (Fig. 5c), NORA3 far 
(a)

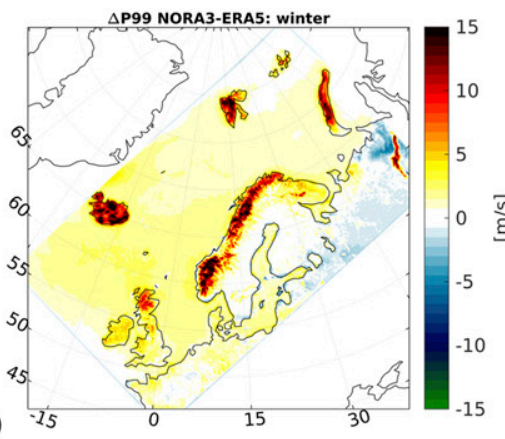

(c)

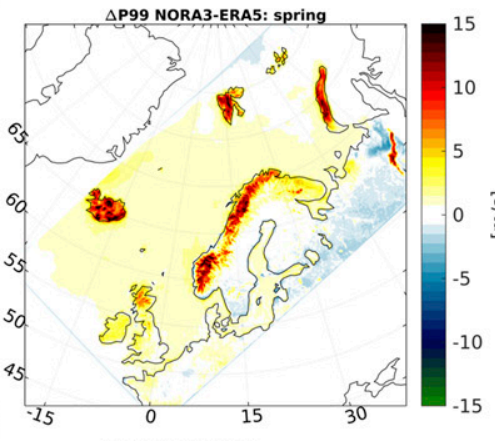

(b)

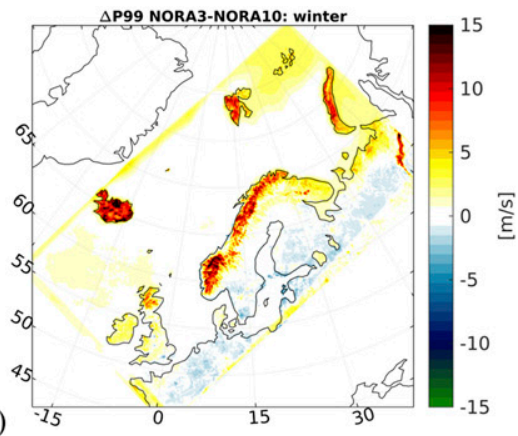

(d)
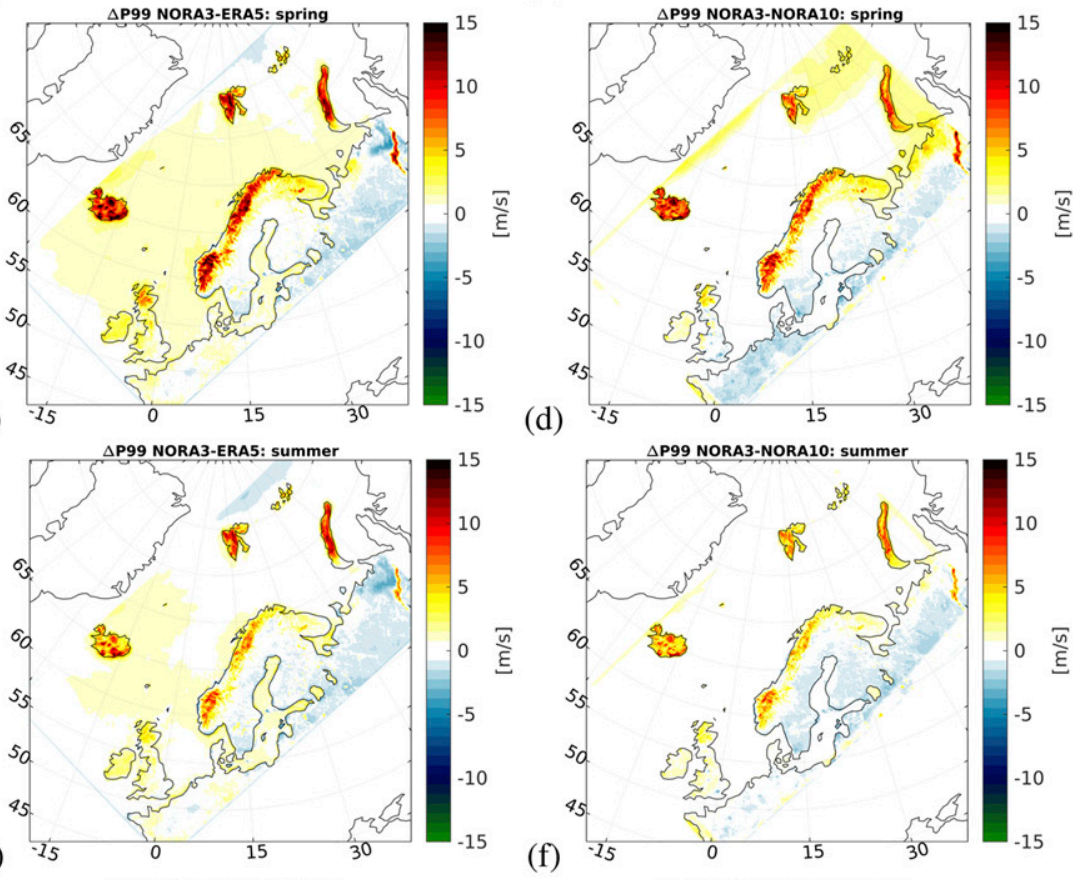

(f)
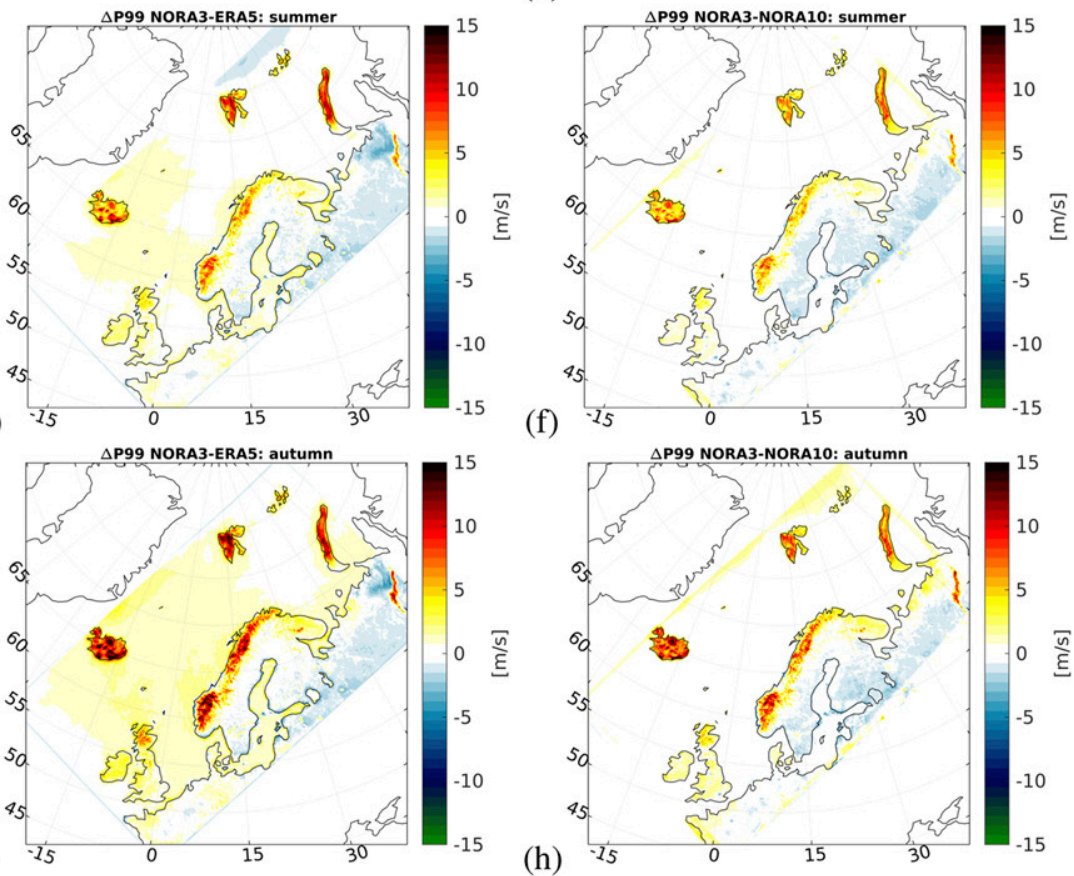

(h)

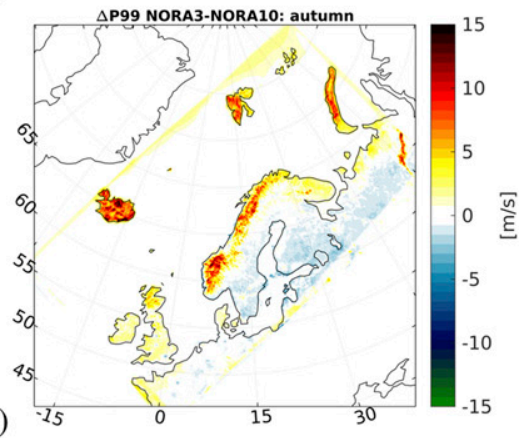

FIG. 10. The 99th-percentile wind field difference (left) between NORA3 and ERA5 and (right) between NORA3 and NORA10 for the period 2004-18 for (a),(b) DJF; (c),(d) MAM; (e),(f) JJA; and (g),(h) SON.

outperforms both ERA5 and NORA10 for all thresholds of wind speed above light breeze. NORA3, although better than NORA10 and ERA5, has a lower ETS at the mountain stations when compared with the other station classes. This highlights the difficulties of correctly modeling mountainous terrain. For Arctic stations (Fig. 5d), NORA3 again clearly outperforms ERA5 and NORA10 above $3.3 \mathrm{~m} \mathrm{~s}^{-1}$, but its performance is weaker than for the maritime and coastal stations for the same reasons as mentioned for the mountain stations.

\section{b. Spatial comparison between NORA3 and ERA5}

The activity (standard deviation of the wind speed) is shown in Fig. 6b, and the difference in activity is shown in Fig. 7. As can be seen, the activity of NORA3 is much higher than ERA5 
TABLE 4. Polar lows where the identification number (ID), center position (CLON and CLAT) and wind speed observations are taken from Rojo et al. (2019). The maximum 10-m wind speeds for the different polar low events are shown for NORA3, ERA5, and NORA10 in the last three columns. The best performance (in comparison with the maximum observed 10-m wind speed) is marked in boldface type.

\begin{tabular}{|c|c|c|c|c|c|c|c|c|c|}
\hline No. & ID & Date & CLON & CLAT & Obs & Obs gust & NORA3 & ERA5 & NORA10 \\
\hline 1 & 78 & 0900 UTC 22 Dec 2006 & 12.0 & 72.1 & 25.3 & 32.1 & 20.4 & 17.5 & 20.6 \\
\hline 2 & 79 & 0900 UTC 26 Dec 2006 & 22.0 & 72.8 & 25.8 & 33.2 & 19.2 & 16.1 & 17.8 \\
\hline 3 & 82 & 0900 UTC 26 Jan 2007 & 14.5 & 69.5 & 26.8 & - & 28.5 & 20.4 & 25.6 \\
\hline 4 & 104 & 1500 UTC 19 Nov 2008 & 15.0 & 69.9 & 29.0 & - & 20.0 & 18.0 & 17.0 \\
\hline 5 & 105 & 0900 UTC 20 Nov 2008 & 7.5 & 68.0 & 32.6 & 38.9 & 28.2 & 24.6 & 27.1 \\
\hline 6 & 108 & 0900 UTC 7 Jan 2009 & 33.0 & 72.5 & 25.8 & 33.7 & 25.5 & 20.3 & 24.5 \\
\hline 7 & 122 & 2100 UTC 30 Jan 2010 & 4.0 & 60.5 & 20.0 & - & 20.9 & 17.5 & 18.9 \\
\hline 8 & 149 & 0900 UTC 7 Feb 2011 & 1.0 & 66.0 & 21.6 & - & 19.2 & 15.1 & 15.6 \\
\hline 9 & 151 & 0300 UTC 11 Mar 2011 & 0.0 & 68.2 & 24.7 & - & 21.1 & 19.5 & 18.6 \\
\hline 10 & 160 & 0300 UTC 28 Nov 2011 & 11.5 & 67.0 & 30.0 & 37.9 & 24.2 & 18.6 & 22.2 \\
\hline 11 & 161 & 1500 UTC 6 Dec 2011 & 3.0 & 59.8 & 26.3 & 35.8 & 21.4 & 17.1 & 18.7 \\
\hline 12 & 162 & 1200 UTC 27 Dec 2011 & 7.0 & 71.3 & 21.6 & 31.6 & 32.8 & 23.3 & 26.8 \\
\hline 13 & 173 & 0900 UTC 1 Feb 2013 & 10.5 & 66.5 & 21.1 & - & 21.5 & 19.0 & 19.3 \\
\hline 14 & 196 & 0900 UTC 24 Nov 2013 & 21.5 & 71.7 & 21.6 & - & 24.3 & 18.3 & 22.6 \\
\hline 15 & 198 & 0900 UTC 30 Nov 2013 & 45.0 & 71.8 & 21.0 & - & 24.6 & 20.3 & 24.5 \\
\hline 16 & 219 & 1500 UTC 26 Dec 2015 & 29.0 & 71.7 & 31.1 & 37.4 & 30.9 & 23.2 & 29.0 \\
\hline 17 & 227 & 0300 UTC 9 Dec 2016 & 31.5 & 70.8 & 30.0 & 37.9 & 26.9 & 22.6 & 26.7 \\
\hline 18 & 230 & 0300 UTC 20 Jan 2017 & 36.0 & 76.5 & 24.7 & 36.8 & 30.7 & 24.1 & 27.5 \\
\hline 19 & 240 & 1500 UTC 22 Nov 2017 & -12.5 & 57.5 & 22.6 & - & 29.9 & 21.0 & 26.0 \\
\hline
\end{tabular}

in mountainous regions. This can probably to a large degree be explained by the more detailed topography of NORA3 and the impact of nonhydrostatic vertical accelerations.

\section{c. Wind speed, upper-percentile statistics}

The median and upper percentiles of the wind speed at offshore stations are summarized in Table 3. NORA3 has the closest fit to the median, the 75th-, and the 99th-percentile wind speed (Fig. 8). NORA10 also shows very good performance, with the best fit to the 90th-98th percentiles. The ERA5 wind speed is again found to be biased low, but its root-mean-square error (RMSE) is very low, and the correlation with the maritime observations is indeed slightly higher than for NORA3.

Figure 9 shows the time series of the 95 th percentiles of $10-\mathrm{m}$ wind speed for NORA3, ERA5 and NORA10 at maritime stations (Fig. 9a), coastal (Fig. 9b), mountain (Fig. 9c) as well as the Arctic stations (Fig. 9d). NORA3 and NORA10 both perform very well at the upper percentiles at maritime stations, with no significant differences between them, while ERA5 underestimates the 95th percentile by $1.4 \mathrm{~m} \mathrm{~s}^{-1}$. NORA3 scores slightly better than NORA10 at the coastal stations (Fig. 9b) but much better at the mountain stations (Fig. 9c). The Arctic stations exhibit a shift in behavior after 2010 resulting from an increase in observation stations (see Fig. A3). After 2011, NORA3 shows very good agreement with the observations.

Figure 10 shows the seasonal (DJF, MAM, JJA, and SON) difference in 99th-percentile 10-m wind speed between NORA3 and ERA5 (Figs. 10a,c,e,g), and between NORA3 and NORA10 (Figs. 10b,d,f,h). The ERA5 wind speed is found to be consistently weaker than NORA3 throughout the maritime domain, but differences in mountainous terrain are much larger because of the lower resolution of ERA5. The 99th percentile of ERA5 is typically $2 \mathrm{~m} \mathrm{~s}^{-1}$ lower than NORA3. NORA10 also displays a field with weaker gradients than NORA3 and a broader low pressure track across the area between Iceland and the British Isles. It is also clear from comparing Figs. 10a,e, i that the winter (DJF) fields of NORA3 exhibit markedly stronger winds near the Norwegian west coast.

\section{d. Polar lows and windstorms}

\section{1) POLAR LOWS}

Rojo et al. (2019) lists a number of polar low events over the Nordic seas tracked using Advanced Very High Resolution Radiometer (AVHRR) imagery. We have investigated all polar lows listed by Rojo et al. (2019) that have a minimum mean sea level pressure value below $980 \mathrm{hPa}$ within the model domain in the period 2004-18. We retrieved the maximum 10-m wind speed within an area extending $0.6^{\circ}$ north and south and $6^{\circ}$ east and west around the observed polar low center from NORA3, ERA5, and NORA10. Table 4 shows that NORA3 has a maximum wind speed value closest to the observed value in 12 of 19 cases. NORA10 performs best in three of the cases, and ERA5 has the most optimal value in four of the cases.

As an illustration of the differences between the two hindcast archives and the ERA5 reanalysis, we have investigated a shortlived but intense polar low that developed east of Bear Island. The polar low was first detected at 0300 UTC 7 January 2009. The low caused severe damage when making landfall in the northernmost part of Finnmark (Magerøya and Honningsvåg). The polar low is described as a multiple, baroclinic, convergence low with a reversed shear in the database for Surface Temperature and Altimeter Synergy for Improved Forecasting of Polar Lows (STARS, see https://projects.met.no/stars/; Furevik et al. 2015). The low was also investigated by Haakenstad et al. (2020).

The initial situation (0300 UTC 7 January 2009) is shown in Fig. 11. An upper-level low is situated ahead of the polar low, 


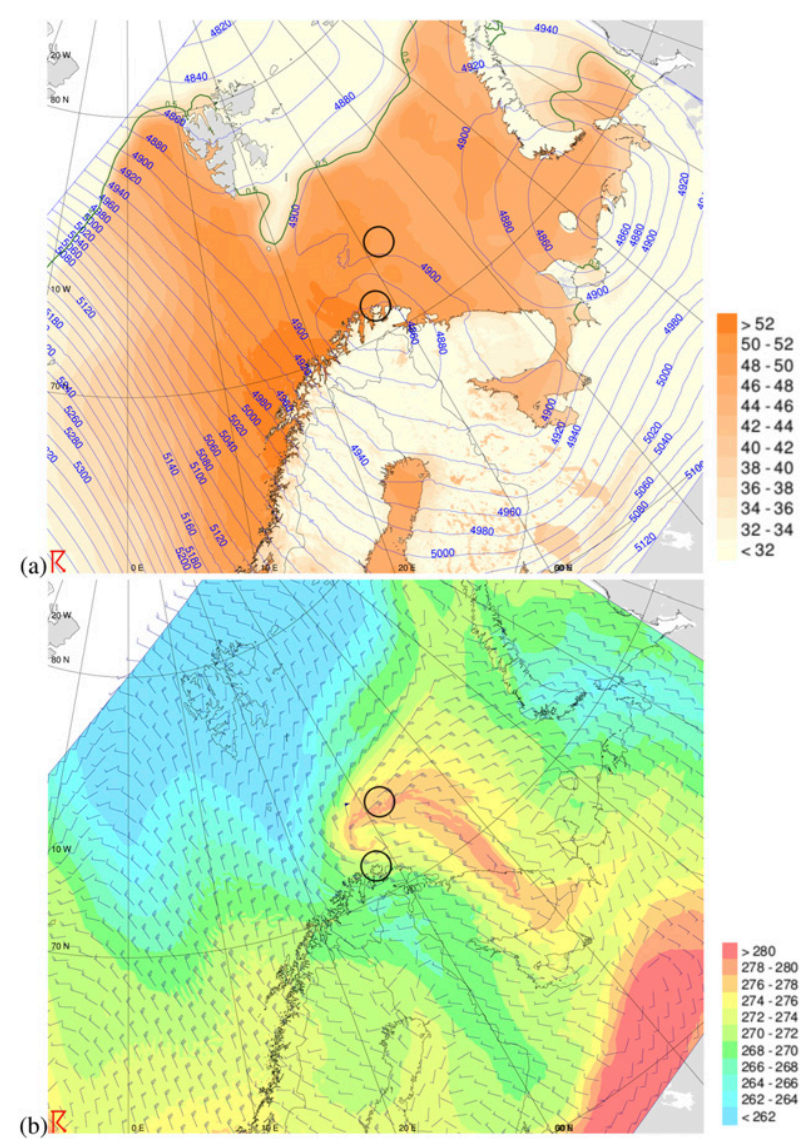

FIG. 11. The NORA3 atmospheric situation at 0300 UTC 7 Jan 2009. (a) The difference between sea surface temperature and the temperature $(\mathrm{K})$ at the $500-\mathrm{hPa}$ level is indicated by orange colors, and the ice edge is indicated in dark green. Blue contour lines show the height of the 500-hPa level. (b) The equivalent potential temperature (K) at $850 \mathrm{hPa}$ and $10-\mathrm{m}$ wind speed, where a large feather on the barb is $10 \mathrm{kt}$, a small feather is $5 \mathrm{kt}$, and triangles indicate $50 \mathrm{kt}\left(1 \mathrm{kt}=0.5 \mathrm{~m} \mathrm{~s}^{-1}\right)$. In (a) and (b), the start position and end position of the polar low are shown by the circles, with the northernmost circle being the start position. (The positions are taken from the STARS database).

over Finnmark in northern Norway (see Fig. 11a), indicating a reversed shear and a typical baroclinically driven initial condition for the formation of the polar low (Reed and Duncan 1987). The ice edge stretches southward east of the Svalbard Archipelago, and open water is present on the western side. This shape of the sea ice edge favors the formation of a downstream convergence zone conducive to mesoscale cyclone development (Sergeev et al. 2018). There is a large temperature difference (49-51 K) between the sea surface and the 500-hPa surface [also documented in the STARS database (Furevik et al. 2015)] and thus also a large atmospheric heat potential. The difference is well above the commonly cited threshold of $43 \mathrm{~K}$ (Zahn and von Storch 2008), above which there is thought to be a $25 \%$ chance of developing a polar low. The temperature difference $T_{\text {sea }}-T_{500}$ modeled by NORA3 mirrors closely the observed situation described in the STARS database, and it is likely that the polar low was intensified by

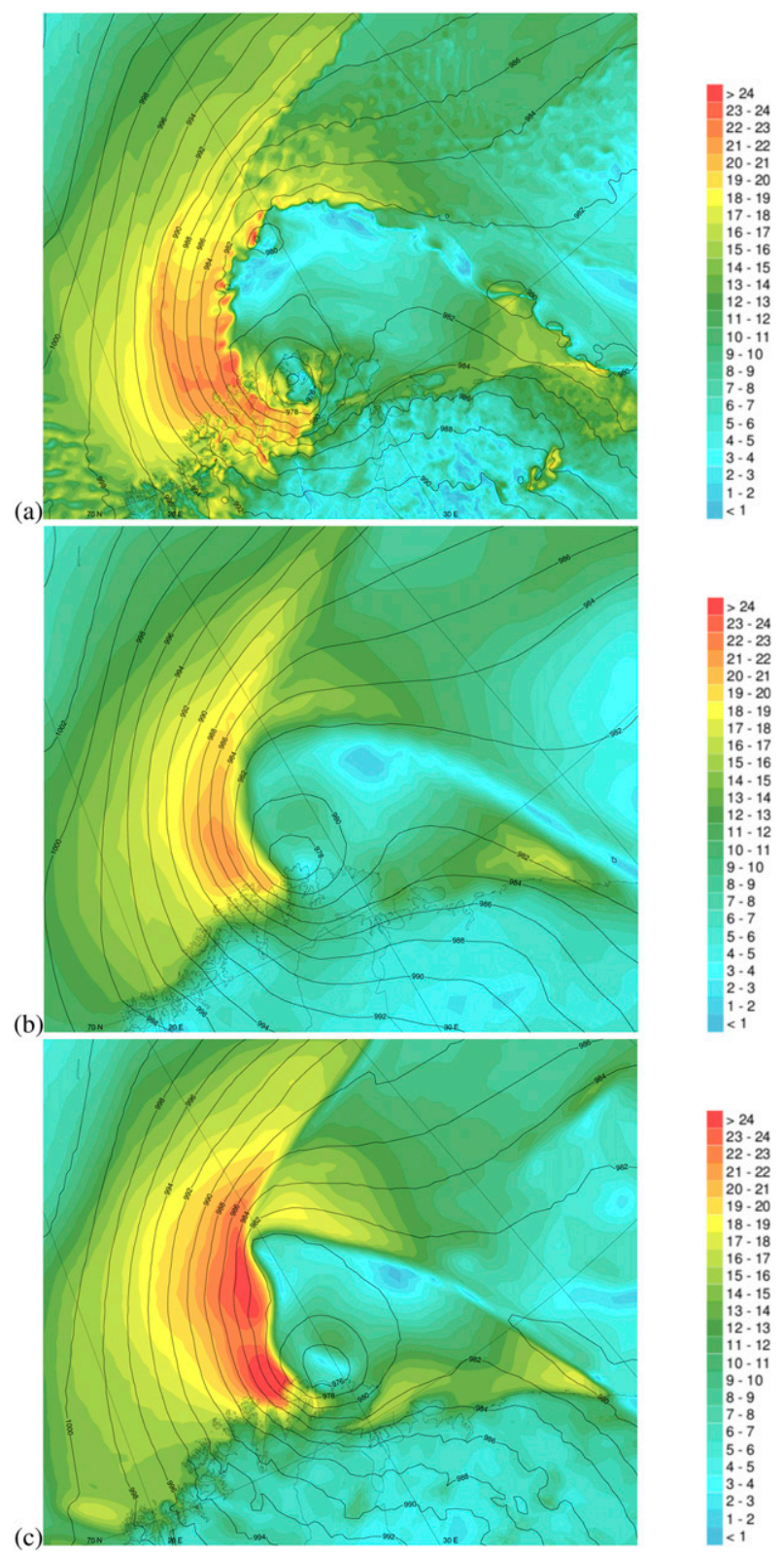

FIG. 12. Polar low at 0900 UTC 7 Jan 2009, showing 10-m wind speed (shading) and MSLP (contours) from (a) NORA3, (b) ERA5, and (c) NORA10.

convective and diabatic processes. Figure 11b shows NORA3's 850 -hPa equivalent potential temperature. A sharp gradient is visible along the ice edge. A cold-air outbreak is evident from the extended sea ice east of Svalbard with prevailing northerly wind transporting stably stratified, dry cold air from the Arctic over warmer water, creating a shallow, secondary baroclinic layer. Figure 12 compares NORA3, ERA5, and NORA10 10-m wind speed (Fig. 12a) and MSLP fields (Fig. 12b) at the mature stage (0900 UTC 7 January 2009). The maximum wind speed value at $0900 \mathrm{UTC}$ is $26 \mathrm{~m} \mathrm{~s}^{-1}$ in NORA3, $22 \mathrm{~m} \mathrm{~s}^{-1}$ in ERA5, and $26 \mathrm{~m} \mathrm{~s}^{-1}$ in NORA10. The NORA3 maximum of 


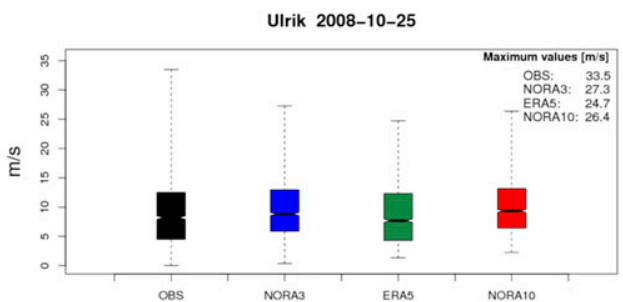

(a)

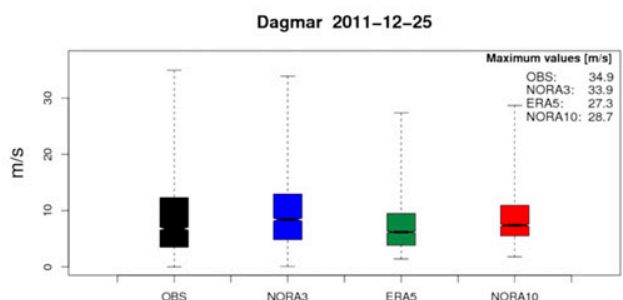

(c)

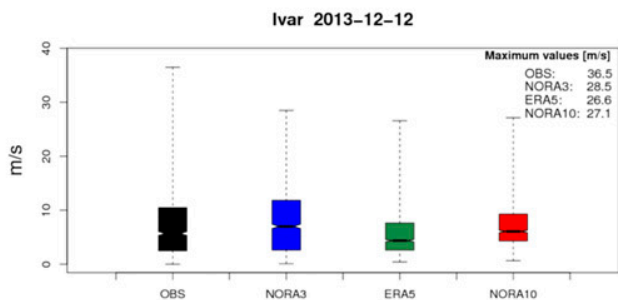

(e)

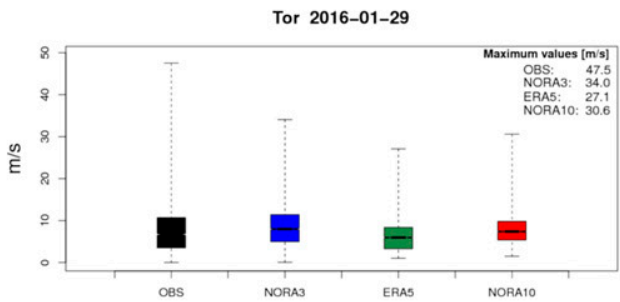

(g)

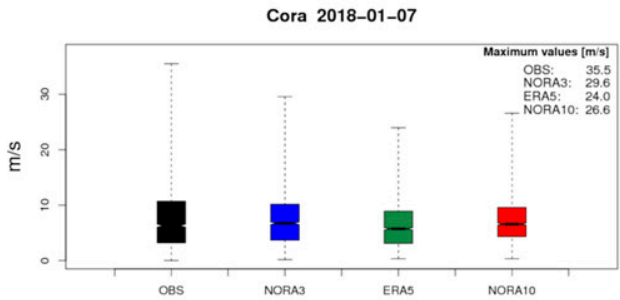

(i)

FIG. 13. Wind speed statistics from observations, NORA3, NORA10, and ERA5 for named windstorms during the period 2008-18. The boxes show the 25th and 75th percentiles and the median. The whiskers show the maximum and minimum values. Stations from counties affected by each windstorm are included (this list deviates from the list shown in Fig. 1 and includes only quality-assured observation stations acquired by the Norwegian Meteorological Institute). (b)

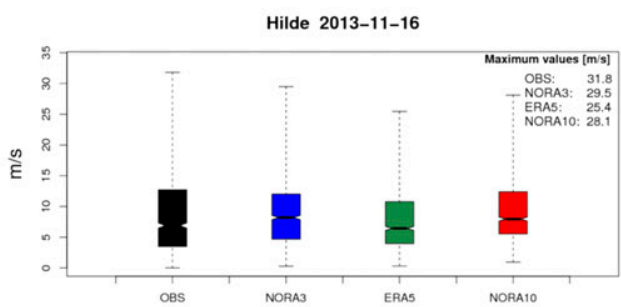

(d)

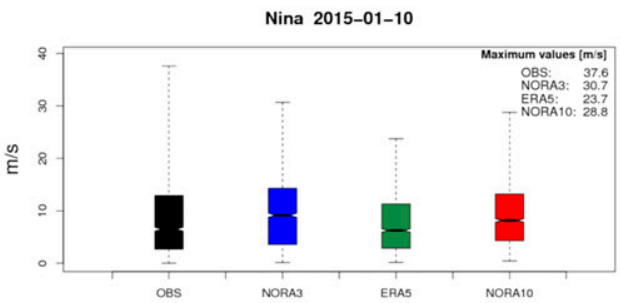

(f)

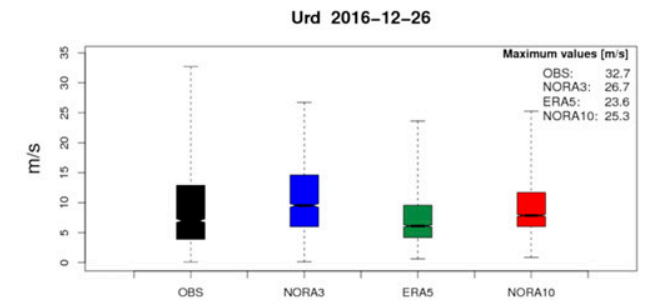

(h)

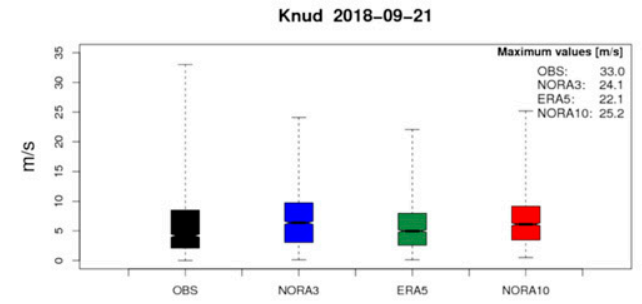

(j)

b)

\section{)}

(f)

)

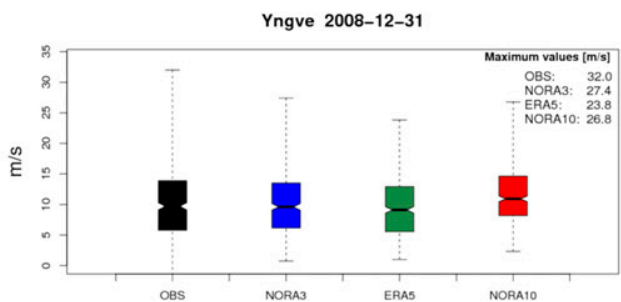

$26 \mathrm{~m} \mathrm{~s}^{-1}$ occurs on the trailing arm in the position $72^{\circ} 51^{\prime} \mathrm{N}$, $29^{\circ} 02^{\prime} \mathrm{E}$ and is far away from the coast, as opposed to NORA10, which has the maximum wind speed in the location where the polar low makes landfall. NORA3 has a maximum 


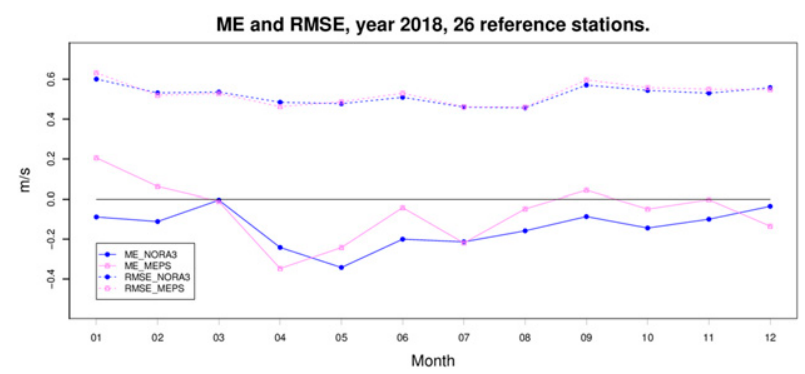

FIG. A1. A comparison between MEPS and NORA3 in terms of mean error and root-mean-square error.

(2015)]. Such convective cells are obviously not present in the fields from NORA10 and ERA5 because they are the result of the convection-permitting nonhydrostatic dynamics of the HARMONIE-AROME model. The polar low centers of NORA3 and ERA5 agree well with the tracked polar low in the STARS database, whereas NORA10 puts the center too far to the northeast.

\section{2) WindSTORMS}

The maximum winds of NORA3, ERA5, and NORA10 during the 10 most important (named) windstorms to hit the
Norwegian mainland in the period 2009-18 have been investigated. All quality-assured observations from the databases of the Norwegian Meteorological Institute (https:// www.met.no/en and https://frost.met.no/index.html) from the affected counties have been compared with collocated wind speeds from NORA3, ERA5, and NORA10. The results are shown as boxplots in Fig. 13. The maximum wind speed (upper whiskers; see also the statistics in the individual panels) is consistently higher (and closer to the observed maximum) in NORA3 than in ERA5. This is also the case with respect to NORA10 except for one case, Knud (Fig. 13j), where NORA3 underestimates the maximum wind speed by $18 \%$. We also note that NORA3's wind speed interquartile distance, a measure of the spread, is closer to the observed interquartile distance. This suggests that not only are the windstorm maxima better modeled, but the spatial variability is also more realistic.

\section{Discussion and concluding remarks}

NORA3 represents the most detailed hindcast study performed to date for the Norwegian Sea, the North Sea, and the Barents Sea. We find a clear improvement when compared with ERA5 in the representation of near-surface winds over the open ocean (cf. Fig. 4), but an even greater improvement in

TABLE A1. Model configuration.

\begin{tabular}{|c|c|}
\hline Domain & $\begin{array}{l}\text { The domain covers the North Sea, the Norwegian Sea, and the Barents Sea; the grid is a Lambert conformal conic } \\
\text { grid, with } 900 \text { longitudinal } \times 1500 \text { latitudinal grid points; the central meridian }=42.0^{\circ} \mathrm{W} \text {, the central latitude }= \\
66.3^{\circ} \mathrm{N} \text {, and the reference parallel }=66.3^{\circ} \mathrm{N}\end{array}$ \\
\hline Horizontal resolution & $3 \mathrm{~km}$ \\
\hline No. of vertical levels & 65 \\
\hline Coupling model & ERA5 (IFS Cycle 41r2, horizontal resolution $31 \mathrm{~km}$, and 137 vertical levels) \\
\hline Initialization method & No initial digital filtering \\
\hline Coupling frequency & 6 hourly \\
\hline Integration hours & 0000, 0600, 1200, and $1800 \mathrm{UTC}$ \\
\hline Forecast range & $9 \mathrm{~h}$ \\
\hline Surface analysis & CANARI \\
\hline Background & OI-Main \\
\hline Observations & $\begin{array}{l}\text { Land surface: synoptic (SYNOP) and METAR; Sea surface: ships (SHIP), drifting buoys (DRIBU), and buoys } \\
\text { (BUOYS) (retrieved from the MARS database) }\end{array}$ \\
\hline Dynamics & Nonhydrostatic, convection permitting; solves the fully compressible Euler equations \\
\hline Discretization & Two-time-level, semi-implicit, semi-Lagrangian discretization using SETTLS; A-grid; linear \\
\hline Time step & $60 \mathrm{~s}$ \\
\hline Microphysics & $\begin{array}{l}\text { ICE3 (Pinty and Jabouille 1998; Lascaux et al. 2006) combined with the OCND2 scheme (Müller et al. 2017b) and } \\
\text { Kogan autoconversion (Khairoutdinov and Kogan 2000) }\end{array}$ \\
\hline \multirow[t]{6}{*}{ Surface } & SURFEX (Le Moigne et al. 2012; Masson et al. 2013) \\
\hline & Land surface model: ISBA-3L (Boone et al. 1999) \\
\hline & $\begin{array}{l}\text { Inland water: prognostic variables are kept constant, and the roughness length is defined by the Charnock } \\
\text { relation } z_{0}=0.015 u_{\circledast}^{2} / g\end{array}$ \\
\hline & Sea surface: ECUME (see Table A3) \\
\hline & Sea ice: SICE (Batrak et al. 2018) \\
\hline & Urban areas: Town energy budget scheme \\
\hline Convection & EDMF-M (Siebesma et al. 2003; Soares et al. 2004; Siebesma et al. 2007; de Rooy and Siebesma 2010) \\
\hline Turbulence & HARATU (van Meijgaard et al. 2012; Lenderink and Holtslag 2004) \\
\hline \multirow{2}{*}{ Radiation } & Longwave: RRTM (Mlawer et al. 1997) \\
\hline & Shortwave: ECMWF operational SW scheme (ECMWF 1989) \\
\hline Aerosols and ozone & Monthly climatologies \\
\hline Physiography & ECOCLIMAP, version 2 \\
\hline Computing platform & The Nebula cluster of the National Supercomputer Centre, located in Linköping \\
\hline
\end{tabular}




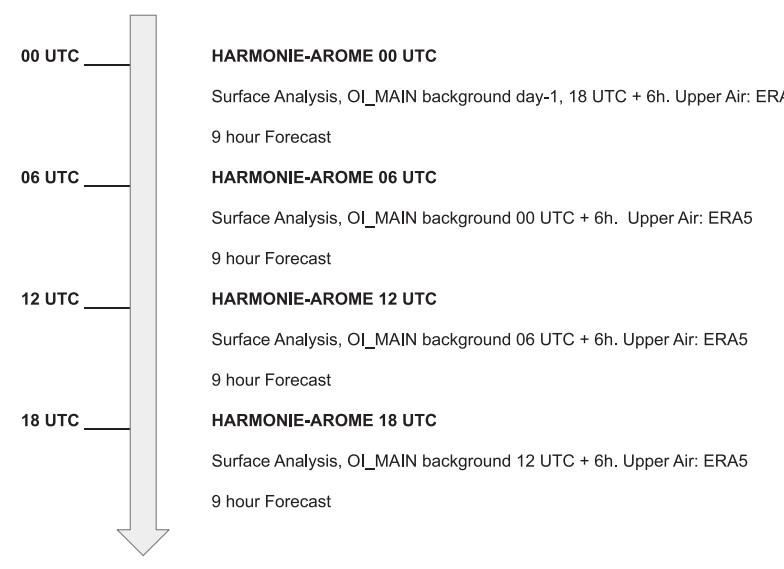

FIG. A2. The NORA3 hindcast production cycle. Four consecutive and partly overlapping 9-hourly forecast cycles with HARMONIE-AROME are shown. Each cycle starts with a surface analysis and upper-air blending of ERA5 fields. A 9-h forecast is then run, of which time steps at $4-9 \mathrm{~h}$ are concatenated onto the previous cycle to form a continuous hindcast archive.

mountainous and coastal terrain (see Fig. 5). NORA3's activity ratio is considerably better than both NORA10 and ERA5. Although NORA10 has only marginally lower mean absolute error for maritime stations and ERA5 in fact exhibits slightly higher correlation than NORA3, the fact that the activity ratio is better in NORA3 means that the wind climate is more realistically modeled by the nonhydrostatic model, even over the open ocean (see Fig. 4). This is also the case for spatial variations, which is seen in the wind field of the polar low. Over land, this becomes much more evident (Fig. 2), and the large annual variations in bias seen in NORA10 are absent. The mean absolute error is also much smaller, and the activity ratio remains closer to unity than for both NORA10 and ERA5.

In the Arctic, NORA3 also shows an improvement of upperpercentile wind speed relative to ERA5 and also to NORA10 (Fig. 5). Müller et al. (2017a) showed that AROME-Arctic adds value to the representation of the surface parameters relative to ECMWF's forecast and reanalysis model systems, a finding that is in agreement with our results. The study by Køltzow et al. (2019) also found the operational AROMEArctic model to have good performance around Svalbard. Further work will also look at the performance of the model setup in terms of extreme rainfall in the steep topography over Svalbard and the Norwegian mainland.

The NORA3 hindcast archive will be used as forcing for high-resolution coastal wave hindcast integrations as well as for extreme value analyses of wind climate. It has thus been important to assess its ability to represent the surface wind field across a range of statistics, from its correlation, bias, and activity to its representation of upper-percentile wind speed and from open ocean conditions to complex coastal terrain. Its performance is generally good, and the improvement over the host analysis is naturally particularly strong in the coastal zone and in mountainous terrain. However, it is clear that there are limits to the performance that can be achieved with stand-alone atmospheric hindcast integrations. A natural extension of such a modeling effort would be to conduct a full three-dimensional or four-dimensional variational data assimilation to achieve a complete reanalysis on a similar resolution. This is, however, very costly [cf. the ongoing effort to create the Copernicus Arctic Regional Reanalysis (CARRA) funded by the Copernicus Climate Change Service]. Another possible extension is to incorporate a wave model into a coupled atmosphere-wave hindcast to account for the feedback between the sea surface roughness controlled by the wave field (Janssen 1989, 1991). This feedback has been shown to be important on larger scales (Janssen et al. 2004), but on the spatial and temporal scales considered here, its impact on the climatology is not expected to be big. It would, however, be a natural next step to attempt a coupled atmosphere-wave hindcast integration on a similar spatial scale $(2-4 \mathrm{~km})$.

The hindcast has been shown to represent the upper percentiles of wind speed much better than the host analysis ERA5, and also better than the older hindcast NORA10. This suggests that the new hindcast should be suitable for extreme value analyses. Topographic effects are much better resolved than in the coarser (hydrostatic) NORA10 hindcast and the

TABLE A2. The ECUME (Le Moigne et al. 2012) scheme.

Roughness length $z_{0}=\left(\alpha u_{*}^{2} / g\right)+\left(\beta \nu / u_{*}\right)$ (Smith 1988), where $\alpha=0.011$ and $\beta=0.11$

Stability functions Modified Businger functions $\psi_{m}$ and $\psi_{h}$ that depend on the Monin-Obukhov parameter $\zeta=z / L$ Stable cases $(\zeta \geq 0): \psi_{m}=\psi_{h}=-\Gamma \zeta$, where $\Gamma=7$

Unstable cases $(\zeta<0): \psi_{m}=(1-f) \psi_{m K}+f \psi_{m C}$ and $\psi_{h}=(1-f) \psi_{h K}+f \psi_{h C}$, where $f=\zeta^{2} /\left(1+\zeta^{2}\right)$, $\psi_{m K}=2 \ln \left(\frac{1+x}{2}\right)+\ln \left(\frac{1+x^{2}}{2}\right)-2 \arctan x+\frac{\pi}{2}$, with $x=(1-16 \zeta)^{1 / 4}(K$ denotes Kansas $), \psi_{h K}=2 \ln \left(\frac{1+x}{2}\right)$, $\psi_{m C}=\frac{3}{2} \ln \left(\frac{y^{2}+y+1}{3}\right)-\sqrt{3} \arctan \left(\frac{2 y+1}{\sqrt{3}}\right)+\frac{\pi}{\sqrt{3}}$, with $y=(1-12.87 \zeta)^{1 / 3}(C$ denotes convective $)$, and $\psi_{h C}=\frac{3}{2} \ln \left(\frac{y^{2}+y+1}{3}\right)-\sqrt{3} \arctan \left(\frac{2 y+1}{\sqrt{3}}\right)+\frac{\pi}{\sqrt{3}}$

Sea surface drag $\quad \tau_{\text {sea }}=-\rho_{a} C_{D} U^{2}+\tau_{p}$ (Fairall et al. 1996)

Sea surface

$H_{\text {sea }}=\rho_{a} c_{p_{a}} C_{H} U\left(\theta_{s}-\theta_{a}\right)+H_{p}($ Gosnell et al. 1995)

heat flux

Sea surface latent $\quad \mathrm{LE}_{\text {sea }}=\rho_{a} \mathscr{L}_{v} C_{E} U\left(q_{s}-q_{a}\right)+\mathrm{LE}_{\mathrm{Webb}}$, where $\mathrm{LE}_{\mathrm{Webb}}$ is an adjustment due to air density variations as the humidity heat flux varies with evaporation Neutral stability 10-m drag coefficient 
TABLE A3. Station list (ID = identifier; WIGOS is the WMO Integrated Global Observing System). Abbreviations are as follows: Categories (Cat): maritime stations (MR), reference stations (RS), coastal stations (CS), mountain stations (MO), and Arctic stations (AS). Station holder (Stn holder): The Norwegian Meteorological Institute (MET), ConocoPhillips (CP), High Mountain Research Station (HMRS), AVINOR (a state-owned limited company that operates most of the civil airports in Norway), Stiftung Alfred-WegenerInstitut Für Polar- und Meeresforschung (AWI), University of Oslo (UiO), and Norwegian Water Resources and Energy Directorate (NVE). Name: airport (AP) and lighthouse (LH).

\begin{tabular}{|c|c|c|c|c|c|c|c|c|}
\hline ID & Name & Height (m) & Stn holder & WIGOS ID & WMO ID & Lon & Lat & Cat \\
\hline SN87110 & Andøya & 10 & MET; AVINOR & 0-20000-0-01010 & 1010 & 16.131 & 69.307 & $\mathrm{RS} ; \mathrm{CS}$ \\
\hline SN23550 & Beitostølen II & 965 & MET & $0-20000-0-01365$ & 1365 & 8.923 & 61.251 & MO \\
\hline SN50540 & Bergen-Florida & 12 & MET & 0-20000-0-01317 & 1317 & 5.333 & 60.383 & RS \\
\hline SN99710 & Bjørnøya & 16 & MET & $0-20000-0-01028$ & 1028 & 18.998 & 74.504 & RS; AS \\
\hline SN82290 & Bod $\varnothing \mathrm{VI}$ & 11 & MET; AVINOR & $0-20000-0-01152$ & 1152 & 14.364 & 67.267 & RS \\
\hline SN71990 & Buholmråsa LH & 18 & MET & 0-20000-0-01259 & 1259 & 10.455 & 64.4013 & CS \\
\hline SN76925 & Draugen & 76 & OKEA AS & $0-578-0-76925$ & 1202 & 7.779 & 64.352 & MR \\
\hline SN76920 & Ekofisk & 114 & $\mathrm{CP}$ & $0-20000-0-01400$ & 1400 & 3.224 & 56.543 & MR \\
\hline SN25830 & Finsevatn & 1210 & HMRS; MET & $0-20000-0-01350$ & 1350 & 7.527 & 60.594 & $\mathrm{MO}$ \\
\hline SN94500 & Fruholmen LH & 13 & MET & $0-20000-0-01055$ & 1055 & 23.982 & 71.094 & RS \\
\hline SN27500 & Færder LH & 6 & MET & $0-20000-0-01482$ & 1482 & 10.524 & 59.027 & $\mathrm{RS} ; \mathrm{CS}$ \\
\hline SN4780 & Gardermoen & 202 & AVINOR & $0-20000-0-01384$ & 1384 & 11.080 & 60.207 & RS \\
\hline SN31970 & Gaustatoppen & 1804 & MET & $0-20000-0-01461$ & 1461 & 8.656 & 59.850 & $\mathrm{MO}$ \\
\hline SN76923 & Gullfaks C & 141 & EQUINOR ASA & 0-20000-0-01300 & 1300 & 2.269 & 61.204 & MR \\
\hline SN71850 & Halten LH & 16 & MET & $0-20000-0-01240$ & 1240 & 9.405 & 64.173 & $\mathrm{CS}$ \\
\hline SN76932 & Heimdal & 71 & EQUINOR ASA & $0-578-0-76932$ & 1404 & 2.227 & 59.574 & MR \\
\hline SN99720 & Hopen & 6 & MET & $0-20000-0-01062$ & 1062 & 25.013 & 76.510 & $\mathrm{RS} ; \mathrm{AS}$ \\
\hline SN32890 & Høydalsmo II & 560 & MET & $0-20000-0-01447$ & 1447 & 8.199 & 59.497 & RS \\
\hline SN99790 & Isfjord Radio & 7 & MET & 0-744-0-99790 & 1013 & 13.619 & 78.063 & AS \\
\hline SN99950 & Jan Mayen & 10 & MET & 0-20000-0-01001 & 1001 & -8.669 & 70.939 & RS; AS \\
\hline SN97251 & Karasjok-Mar. & 131 & MET & $0-20000-0-01065$ & 1065 & 25.502 & 69.464 & RS \\
\hline SN99935 & Karl XII-Øуа & 5 & MET & 0-20000-0-01009 & 1009 & 25.005 & 80.652 & AS \\
\hline SN93700 & Kautokeino & 307 & MET & 0-20000-0-01047 & 1047 & 23.034 & 68.997 & $\mathrm{RS}$ \\
\hline SN99370 & Kirkenes AP & 89 & AVINOR & 0-20000-0-01089 & 1089 & 29.898 & 69.726 & CS \\
\hline SN39040 & Kjevik & 12 & MET & $0-20000-0-01452$ & 1452 & 8.077 & 58.200 & $\mathrm{CS}$ \\
\hline SN99740 & Kongsøya & 20 & MET; UiO & $0-20000-0-01016$ & 1016 & 28.888 & 78.907 & AS \\
\hline SN13160 & Kvitfjell & 1030 & MET & 0-20000-0-01375 & 1375 & 10.128 & 61.465 & MO \\
\hline SN99938 & Kvitøya & 10 & MET & 0-20000-0-01011 & 1011 & 31.459 & 80.104 & AS \\
\hline SN42160 & Lista LH & 14 & MET & $0-20000-0-01427$ & 1427 & 6.568 & 58.109 & $\mathrm{RS} ; \mathrm{CS}$ \\
\hline SN98400 & Makkaur LH & 9 & MET & $0-20000-0-01092$ & 1092 & 30.07 & 70.706 & CS \\
\hline SN61410 & Mannen & 1294 & NVE & $0-20000-0-01220$ & 1220 & 7.770 & 62.460 & MO \\
\hline SN53530 & Midtstova & 1162 & BANE NOR & $0-20000-0-01346$ & 1346 & 7.276 & 60.656 & MO \\
\hline SN80610 & Myken & 17 & MET & $0-20000-0-01115$ & 1115 & 12.486 & 66.763 & $\mathrm{RS} ; \mathrm{CS}$ \\
\hline SN31620 & Møsstrand II & 977 & MET & $0-20000-0-01450$ & 1450 & 8.179 & 59.840 & MO \\
\hline SN39100 & Oksøy LH & 9 & MET & $0-20000-0-01448$ & 1448 & 8.053 & 58.073 & $\mathrm{RS} ; \mathrm{CS}$ \\
\hline SN62480 & Ona II & 20 & MET & 0-20000-0-01212 & 1212 & 6.538 & 62.859 & $\mathrm{RS} ; \mathrm{CS}$ \\
\hline SN18700 & Oslo-Blindern & 94 & MET & $0-20000-0-01492$ & 1492 & 10.720 & 59.942 & RS \\
\hline SN76750 & Sandnessjøen LH & 17 & AVINOR & 0-20000-0-01116 & 1116 & 12.478 & 65.964 & $\mathrm{CS}$ \\
\hline SN75550 & Sklinna LH & 23 & MET & $0-20000-0-01102$ & 1102 & 10.997 & 65.202 & $\mathrm{RS} ; \mathrm{CS}$ \\
\hline SN85380 & Skrova LH & 14 & MET & $0-20000-0-01160$ & 1160 & 14.649 & 68.154 & $\mathrm{RS} ; \mathrm{CS}$ \\
\hline SN76926 & Sleipner A & 135 & EQUINOR ASA & $0-578-0-76926$ & 1402 & 1.909 & 58.371 & MR \\
\hline SN96400 & Slettnes LH & 8 & MET & 0-20000-0-01078 & 1078 & 28.217 & 71.089 & $\mathrm{RS} ; \mathrm{CS}$ \\
\hline SN44560 & Sola & 7 & AVINOR; MET & 0-20000-0-01415 & 1415 & 5.637 & 58.884 & $\mathrm{RS} ; \mathrm{CS}$ \\
\hline SN17000 & Strømtangen LH & 10 & MET.NO & 0-20000-0-01495 & 1495 & 10.829 & 59.151 & CS \\
\hline SN65940 & Sula & 5 & MET.NO & $0-20000-0-01228$ & 1228 & 8.467 & 63.847 & CS \\
\hline SN99840 & Svalbard AP & 28 & AVINOR; MET & $0-20000-0-01008$ & 1008 & 15.502 & 78.245 & $\mathrm{RS}$; AS \\
\hline SN59800 & Svinøy LH & 38 & MET & $0-20000-0-01205$ & 1205 & 5.268 & 62.329 & RS; CS \\
\hline SN85450 & Svolvær AP & 9 & AVINOR & $0-20000-0-01161$ & 1161 & 14.669 & 68.245 & CS \\
\hline SN99752 & Sørkappøya & 10 & MET.NO & 0-20000-0-01020 & 1020 & 16.543 & 76.473 & AS \\
\hline SN36200 & Torungen LH & 12 & MET & $0-20000-0-01465$ & 1465 & 8.789 & 58.399 & $\mathrm{RS} ; \mathrm{CS}$ \\
\hline SN76931 & Troll A & 92 & EQUINOR ASA & 0-20000-0-01309 & 1309 & 3.719 & 60.644 & MR \\
\hline SN90450 & Troms $\varnothing$ & 100 & MET & 0-20000-0-01026 & 1026 & 18.937 & 69.654 & RS \\
\hline SN47300 & Utsira LH & 55 & MET & $0-20000-0-01403$ & 1403 & 4.872 & 59.307 & RS \\
\hline
\end{tabular}


TABLE A3. (Continued)

\begin{tabular}{clccccccc}
\hline \hline \multicolumn{1}{c}{ ID } & \multicolumn{1}{c}{ Name } & Height $(\mathrm{m})$ & Stn holder & WIGOS ID & WMO ID & Lon & Lat & Cat \\
\hline SN98550 & Vardø Radio & 10 & MET & $0-20000-0-01098$ & 1098 & 31.096 & 70.371 & RS; CS \\
SN13420 & Venabu & 930 & MET & $0-20000-0-01380$ & 1380 & 10.108 & 61.651 & MO \\
SN99927 & Verlegenhuken & 8 & MET & $0-20000-0-01002$ & 1002 & 16.243 & 80.056 & AS \\
SN60990 & Vigra & 22 & AVINOR & $0-20000-0-01210$ & 1210 & 6.115 & 62.5617 & CS \\
SN57770 & Ytterøyane LH & 26 & MET & $0-20000-0-01304$ & 1304 & 4.682 & 61.572 & CS \\
SN71550 & Ørland III & 10 & MET & $0-20000-0-01241$ & 1241 & 9.611 & 63.705 & RS; CS \\
\hline
\end{tabular}

host analysis, ERA5. This is particularly important in fjord systems, where the wind field is dominated by local effects (Christakos et al. 2020a,b).

Acknowledgments. This study was carried out with support from the ERA4CS WINDSURFER project and the Norwegian Climate Service Centre (KSS). We gratefully acknowledge the support from Equinor ASA who have cofunded the development of the NORA3 archive. Authors Reistad, Aarnes, and Breivik gratefully acknowledge the Research Council of Norway for funding through the ExWaMar project (Grant 256466). Authors Furevik and Haakenstad are grateful for funding from the Norwegian Public Roads Administration through the project "E39 Coastal Highway Route."

Data availability statement. The data will be archived on The Norwegian Meteorological Institute's publicly accessible Thredds server (https://thredds.met.no). Quality-assured offshore (maritime)

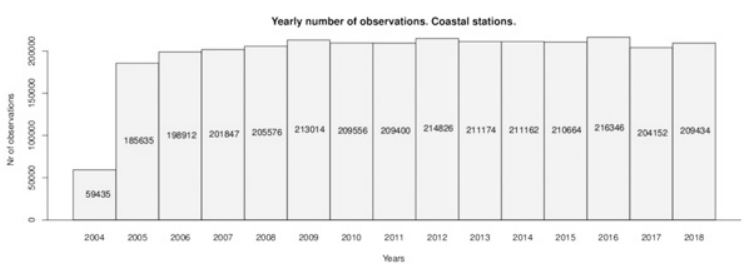

(a)

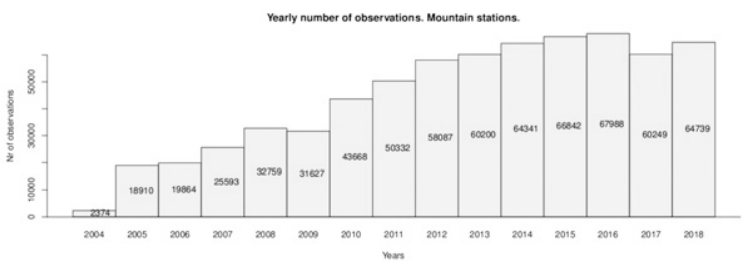

(b)

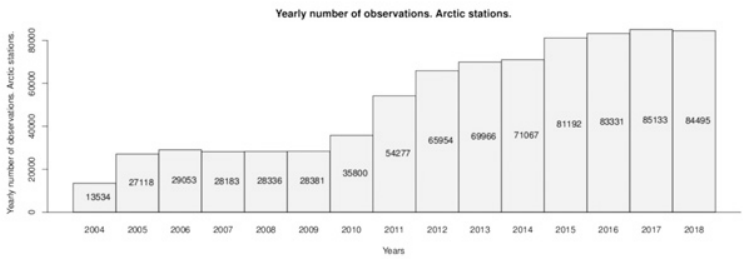

(c)

FIG. A3. Observation count: (a) coastal, (b) mountain, and (c) Arctic stations. and land-based observing stations used in this study are retrieved from the Norwegian Meteorological Institute (https:// www.met.no/en and https://frost.met.no/index.html).

\section{APPENDIX}

\section{Details of the Model Performance, Model Configuration, and Observation Network}

\section{a. A comparison of NORA3 and the short-range ensemble} forecast system for the Nordic countries

To investigate how the performance of NORA3 is affected by the choice of $3-\mathrm{km}$ resolution, we have compared the NORA3 10-m wind speed at the reference stations on the Norwegian mainland in 2018 with the operational short-range ensemble prediction system (MEPS) forecasts (Müller et al. 2017b). MEPS runs the 2.5-km HARMONIE-AROME model with full 3DVAR assimilation. The assimilation will favor the operational forecasts, and deviations from the MEPS results must be expected. The comparison (Fig. A1) has been performed by using the $10-\mathrm{m}$ wind speed at 6 -h lead time for both models. It is clear from Fig. A1 that the differences are marginal, both in terms of mean error and RMSE.

\section{b. Model configuration}

The model setup is outlined in Table A1, and the sequence of 9-hourly forecast cycles is shown in Fig A2. The ECUME scheme is outlined in Table A2.

\section{c. Observing stations}

All observing stations are listed in Table A3. The annual number of coastal, mountain, and Arctic observations are shown in Fig. A3. The reason why there are so few observations in 2004 for all station categories is that only observations with the strictest quality (Kielland 2005) have been used in the validation, and before 2005 there were only a few observations that fulfilled this requirement.

\section{REFERENCES}

Aarnes, O. J., S. Abdalla, J.-R. Bidlot, and Ø. Breivik, 2015: Marine wind and wave height trends at different ERA-Interim forecast ranges. J. Climate, 28, 819-837, https://doi.org/10.1175/ JCLI-D-14-00470.1.

- and Coauthors, 2017: Projected changes in significant wave height towards the end of the 21st century: Northeast Atlantic. J. Geophys. Res. Oceans, 122, 3394-3403, https://doi.org/ 10.1002/2016JC012521. 
ALADIN International Team, 1997: The ALADIN project: Mesoscale modelling seen as basic tool for weather forecasting and atmospheric research. WMO Bull., 46, 317-324.

Andersen, O. J., and J. Løvseth, 2006: The Frøya database and maritime boundary layer wind description. Mar. Structures, 19, 173-192, https://doi.org/10.1016/j.marstruc.2006.07.003.

Batrak, Y., E. Kourzeneva, and M. Homleid, 2018: Implementation of a simple thermodynamic sea ice scheme, SICE version 1.038h1, within the ALADIN-HIRLAM numerical weather prediction system version 38h1. Geosci. Model Dev., 11, 33473368, https://doi.org/10.5194/gmd-11-3347-2018.

Belamari, S., 2005: Report on uncertainty estimates of an optimal bulk formulation for surface turbulent fluxes. Marine Environment and Security for the European Area-Integrated Project Tech. Rep., 29 pp.

— mentum fluxes using the ORCA2-LIM global ocean-ice model. Marine Environment and Security for the European Area-Integrated Project Tech. Rep., 88 pp.

Bénard, P., J. Vivoda, J. Mašek, P. Smolíková, K. Yessad, C. Smith, R. Brožková, and J.-F. Geleyn, 2010: Dynamical kernel of the Aladin-NH spectral limited-area model: Revised formulation and sensitivity experiments. Quart. J. Roy. Meteor. Soc., 136, 155-169, https://doi.org/10.1002/qj.522.

Bengtsson, L., and Coauthors, 2017: The HARMONIE-AROME model configuration in the ALADIN-HIRLAM NWP system. Mon. Wea. Rev., 145, 1919-1935, https://doi.org/10.1175/ MWR-D-16-0417.1.

Bitner-Gregersen, E., and Coauthors, 2018: Climate change and safe design of ship structures. Ocean Eng., 149, 226-237, https://doi.org/10.1016/j.oceaneng.2017.12.023.

Boone, A., J. C. Calvet, and J. Noilhan, 1999: Inclusion of a third soil layer in a land surface scheme using the force-restore method. J. Appl. Meteor., 38, 1611-1630, https://doi.org/ 10.1175/1520-0450(1999)038<1611:IOATSL > 2.0.CO;2.

Breivik, Ø., and O. J. Aarnes, 2017: Efficient bootstrap estimates for tail statistics. Nat. Hazards Earth Syst. Sci., 17, 357-366, https://doi.org/10.5194/nhess-17-357-2017.

_, Y. Gusdal, B. R. Furevik, O. J. Aarnes, and M. Reistad, 2009: Nearshore wave forecasting and hindcasting by dynamical and statistical downscaling. J. Mar. Syst., 78, S235-S243, https:// doi.org/10.1016/j.jmarsys.2009.01.025.

— O. O. Aarnes, J.-R. Bidlot, A. Carrasco, and Ø. Sætra, 2013: Wave extremes in the northeast Atlantic from ensemble forecasts. J. Climate, 26, 7525-7540, https://doi.org/10.1175/ JCLI-D-12-00738.1.

— O. Aarnes, S. Abadalla, J.-R. Bidlot, and P. Janssen, 2014: Wind and wave extremes over the world oceans from very large ensembles. Geophys. Res. Lett., 41, 5122-5131, https:// doi.org/10.1002/2014GL060997.

Bricheno, L. M., and J. Wolf, 2018: Future wave conditions of Europe, in response to high-end climate change scenarios. J. Geophys. Res. Oceans, 123, 8762-8791, https://doi.org/ 10.1029/2018JC013866.

Brousseau, P., Y. Seity, D. Ricard, and J. Léger, 2016: Improvement of the forecast of convective activity from the AROME-France system. Quart. J. Roy. Meteor. Soc., 142, 2231-2243, https:// doi.org/10.1002/qj.2822.

Bubnová, R., G. Hello, P. Bénard, and J.-F. Geleyn, 1995: Integration of the fully elastic equations cast in the hydrostatic pressure terrain-following coordinate in the framework of the ARPEGE/ Aladin NWP system. Mon. Wea. Rev., 123, 515-535, https:// doi.org/10.1175/1520-0493(1995)123<0515:IOTFEE>2.0.CO;2.
Catto, J. L., and Coauthors, 2019: The future of midlatitude cyclones. Curr. Climate Change Rep., 5, 407-420, https://doi.org/ 10.1007/s40641-019-00149-4.

Charnock, H., 1955: Wind stress on a water surface. Quart. J. Roy. Meteor. Soc., 81, 639-640, https://doi.org/10.1002/qj.49708135027.

Christakos, K., J.-V. Björkqvist, L. Tuomi, B. R. Furevik, and Ø. Breivik, 2020a: Modelling wave growth in narrow fetch geometries: The white-capping and wind input formulations. Ocean Modell., 157, 101730, https://doi.org/10.1016/j.ocemod.2020.101730.

— B. R. Furevik, O. J. Aarnes, Ø. Breivik, L. Tuomi, and $\varnothing$. Byrkjedal, 2020b: The importance of wind forcing in fjord wave modelling. Ocean Dyn., 70, 57-75, https://doi.org/10.1007/s10236019-01323-w.

Daley, R., 1991: Atmospheric Data Analysis. Atmospheric and Space Science Series, Vol. 2, Cambridge University Press, 460 pp.

Danielson, J., and D. Gesch, 2011: Global multi-resolution terrain elevation data 2010 (GMTED2010). U.S. Geological Survey Tech. Rep. 2011-1073, 26 pp., https://pubs.usgs.gov/of/2011/ 1073/pdf/of2011-1073.pdf.

Dee, D. P., and Coauthors, 2011: The ERA-Interim reanalysis: Configuration and performance of the data assimilation system. Quart. J. Roy. Meteor. Soc., 137, 553-597, https://doi.org/ 10.1002/qj.828.

Deng, A., and D. R. Stauffer, 2006: On improving 4-km mesoscale model simulations. J. Appl. Meteor. Climatol., 45, 361-381, https://doi.org/10.1175/JAM2341.1.

de Rooy, W. C., and A. P. Siebesma, 2008: A simple parameterization for detrainment in shallow cumulus. Mon. Wea. Rev., 136, 560-576, https://doi.org/10.1175/2007MWR2201.1.

— , and — 2010: Analytical expressions for entrainment and detrainment in cumulus convection. Quart. J. Roy. Meteor. Soc., 136, 1216-1227, https://doi.org/10.1002/qj.640.

Donelan, M. A., and A. K. Magnusson, 2017: The making of the Andrea wave and other rogues. Sci. Rep., 7, 44124, https:// doi.org/10.1038/srep44124.

ECMWF, 1989: ECMWF forecast model: Physical parameterization. ECMWF Res. Manual RM-3, 154 pp.

Fairall, C. W., E. F. Bradley, D. P. Rogers, J. B. Edson, and G. S. Young, 1996: Bulk parameterization of air-sea fluxes for Tropical Ocean-Global Atmosphere Coupled-Ocean Atmosphere Response Experiment. J. Geophys. Res., 101, 3747-3764, https://doi.org/ 10.1029/95JC03205.

Faroux, S., A. T. K. Tchuentè, J. L. Roujean, V. Masson, E. Martin, and P. Le Moigne, 2013: ECOCLIMAP-II/Europe: A twofold database of ecosystems and surface parameters at $1 \mathrm{~km}$ resolution based on satellite information for use in land surface, meteorological and climate models. Geosci. Model Dev., 6, 563-582, https://doi.org/10.5194/gmd-6-563-2013.

Føre, I., J. Kristjánsson, Ø. Sætra, Ø. Breivik, B. Røsting, and M. Shapiro, 2011: The full life cycle of a polar low over the Norwegian Sea probed by three research aircraft flights. Quart. J. Roy. Meteor. Soc., 137, 1659-1673, https://doi.org/ 10.1002/qj.825.

Furevik, B. R., and H. Haakenstad, 2012: Near-surface marine wind profiles from rawinsonde and NORA10 hindcast. J. Geophys. Res., 117, D23106, https://doi.org/10.1029/2012JD018523.

— - H. Schyberg, G. Noer, F. Tveter, and J. Röhrs, 2015: ASAR and ASCAT in polar low situations. J. Atmos. Oceanic Technol., 32, 783-792, https://doi.org/10.1175/JTECH-D-1400154.1.

Gandin, L. S., and A. H. Murphy, 1992: Equitable skill scores for categorical forecasts. Mon. Wea. Rev., 120, 361-370, https:// doi.org/10.1175/1520-0493(1992)120<0361:ESSFCF>2.0.CO;2. 
Gaslikova, L., and R. Weisse, 2006: Estimating near-shore wave statistics from regional hindcasts using downscaling techniques. Ocean Dyn., 56, 26-35, https://doi.org/10.1007/s10236005-0041-2.

Gerard, L., J.-M. Piriou, R. Brozkova, J.-F. Geleyn, and D. Banciu, 2009: Cloud and precipitation parameterization in a meso-gamma-scale operational weather prediction model. Mon. Wea. Rev., 137, 3960-3977, https://doi.org/ 10.1175/2009MWR2750.1.

Giard, D., and E. Bazile, 2000: Implementation of a new assimilation scheme for soil and surface variables in a global NWP model. Mon. Wea. Rev., 128, 997-1015, https://doi.org/10.1175/ 1520-0493(2000)128<0997:IOANAS >2.0.CO;2.

Gosnell, R. C., C. Fairall, and P. J. Webster, 1995: The sensible heat of rainfall in the tropical ocean. J. Geophys. Res., 100, 18 43718 442, https://doi.org/10.1029/95JC01833.

Gramstad, O., E. Bitner-Gregersen, Ø. Breivik, A. K. Magnusson, M. Reistad, and O. J. Aarnes, 2018: Analysis of rogue waves in North-Sea in-situ surface wave data. Proc. 37th Int. Conf. on Ocean, Offshore and Arctic Engineering, Madrid, Spain, ASME, V003T02A005, https://doi.org/10.1115/OMAE201877858.

Haakenstad, H., Ø. Breivik, M. Reistad, and O. J. Aarnes, 2020: NORA10EI: A revised regional atmosphere-wave hindcast for the North Sea, the Norwegian Sea and the Barents Sea. Int. J. Climatol., 40, 4347-4373, https://doi.org/10.1002/joc.6458.

Hersbach, H., and Coauthors, 2020: The ERA5 global reanalysis. Quart. J. Roy. Meteor. Soc., 146, 1999-2049, https://doi.org/ 10.1002/qj.3803.

HIRLAM Consortium, 2016: Quality assessment of Harmonie Cycle 40 for use in operational Hirlam systems. KNMI Note, $22 \mathrm{pp}$.

Hodges, K., R. Lee, and L. Bengtsson, 2011: A comparison of extratropical cyclones in recent reanalyses ERA-Interim, NASA MERRA, NCEP CFSR, and JRA-25. J. Climate, 24, 48884906, https://doi.org/10.1175/2011JCLI4097.1.

Hortal, M., 2002: The development and testing of a new two-timelevel semi-Lagrangian scheme (SETTLS) in the ECMWF forecast model. Quart. J. Roy. Meteor. Soc., 128, 1671-1687, https://doi.org/10.1002/qj.200212858314.

Janssen, P., 1989: Wave-induced stress and the drag of air flow over sea waves. J. Phys. Oceanogr., 19, 745-754, https://doi.org/ 10.1175/1520-0485(1989)019<0745:WISATD >2.0.CO;2.

_ 1991: Quasi-linear theory of wind-wave generation applied to wave forecasting. J. Phys. Oceanogr., 21, 1631-1642, https://doi.org/10.1175/1520-0485(1991)021<1631:QLTOWW> 2.0.CO;2.

—, O. Sætra, C. Wettre, H. Hersbach, and J. Bidlot, 2004: Impact of the sea state on the atmosphere and ocean. Ann. Hydrogr., 772, 143-157.

Khairoutdinov, M., and Y. Kogan, 2000: A new cloud physics parameterization in a large-eddy simulation model of marine stratocumulus. Mon. Wea. Rev., 128, 229-243, https://doi.org/ 10.1175/1520-0493(2000)128<0229:ANCPPI >2.0.CO;2.

Kielland, G., 2005: KVALOBS-The quality assurance system of Norwegian Meteorological Institute observations. WMO Instruments and Observing Methods Rep. 82, WMO/TD-1265, 5 pp., https://library.wmo.int/doc_num.php?explnum_id=9293.

Køltzow, M., B. Casati, T. Haiden, and T. Valkonen, 2019: An NWP model intercomparison of surface weather parameters in the European Arctic during the Year of Polar Prediction Special Observing Period Northern Hemisphere 1. Wea. Forecasting, 34, 959-983, https://doi.org/10.1175/WAF-D-190003.1.
Lafore, L., and Coauthors, 1998: The Meso-NH Atmospheric Simulation System. Part I: Adiabatic formulation and control simulations. Ann. Geophys., 16, 90-109, https://doi.org/10.1007/ s00585-997-0090-6.

Laprise, R., 1992: The Euler equations of motion with hydrostatic pressure as an independent variable. Mon. Wea. Rev., 120, 197-207, https://doi.org/10.1175/1520-0493(1992)120<0197: TEEOMW $>2.0 . \mathrm{CO} ; 2$.

Lascaux, F., E. Richard, and J.-P. Pinty, 2006: Numerical simulations of three different MAP IOPs and the associated microphysical processes. Quart. J. Roy. Meteor. Soc., 132, 1907-1926, https:// doi.org/10.1256/qj.05.197.

Le Moigne, P., and Coauthors, 2012: SURFEX scientific documentation. CNRM/GAME Météo-France/CNRS Sci. Doc., 237 pp., https://www.umr-cnrm.fr/surfex/IMG/pdf/surfex_scidoc_v2-2.pdf.

Lenderink, G., and A. A. Holtslag, 2004: An updated length-scale formulation for turbulent mixing in clear and cloudy boundary layers. Quart. J. Roy. Meteor. Soc., 130, 3405-3427, https:// doi.org/10.1256/qj.03.117.

Malardel, S., 2013: Physics/dynamics coupling at very high resolution: Permitted versus parametrized convection. ECMWF Seminar on Numerical Methods for Atmosphere and Ocean Modelling, Reading, United Kingdom, ECMWF, 83-98, https:// www.ecmwf.int/node/10948.

Masson, V., and Coauthors, 2013: The SURFEXv7.2 land and ocean surface platform for coupled or offline simulation of earth surface variables and fluxes. Geosci. Model Dev., 6, 929960, https://doi.org/10.5194/gmd-6-929-2013.

Meucci, A., I. R. Young, and Ø. Breivik, 2018: Wind and wave extremes from atmosphere and wave model ensembles. J. Climate, 31, 8819-8842, https://doi.org/10.1175/JCLI-D-18-0217.1.

$\_,-$O. J. Aarnes, and Ø. Breivik, 2020: Comparison of wind speed and wave height trends from twentieth century models and satellite altimeters. J. Climate, 33, 611-624, https://doi.org/ 10.1175/JCLI-D-19-0540.1.

Mlawer, E. J., S. J. Taubman, P. D. Brown, M. J. Iacono, and S. A. Clough, 1997: Radiative transfer for inhomogeneous atmospheres: RRTM, a validated correlated-k model for the longwave. J. Geophys. Res., 102, 16 663-16 682, https://doi.org/ 10.1029/97JD00237.

Moore, G. W. K., I. A. Renfrew, B. E. Harden, and S. H. Mernild, 2015: The impact of resolution on the representation of Greenland barrier winds and katabatic flows. Geophys. Res. Lett., 42, 3011-3018, https://doi.org/10.1002/2015GL063550.

- D. H. Bromwich, A. B. Wilson, I. Renfrew, and L. Bai, 2016: Arctic system reanalysis improvements in topographicallyforced winds near Greenland. Quart. J. Roy. Meteor. Soc., 142, 2033-2045, https://doi.org/10.1002/qj.2798.

Morim, J., and Coauthors, 2019: Robustness and uncertainties in global multivariate wind-wave climate projections. Nat. Climate Change, 9, 711-718, https://doi.org/10.1038/s41558-019-0542-5.

Müller, M., Y. Batrak, J. Kristiansen, M. A. Ø. Køltzow, and G. Noer, 2017a: Characteristics of a convective-scale weather forecasting system for the European Arctic. Mon. Wea. Rev., 145, 4771-4787, https://doi.org/10.1175/MWR-D-17-0194.1.

, and Coauthors, 2017b: AROME-MetCoOp: A Nordic convective-scale operational weather prediction model. Wea. Forecasting, 32, 609-627, https://doi.org/10.1175/WAF-D-160099.1.

NORSOK, 2007: NORSOK standard N-003: Action and action effects. Standards Norway Doc., 57 pp.

Pinty, J.-P., and P. Jabouille, 1998: A mixed-phase cloud parameterization for use in a mesoscale non-hydrostatic model: 
Simulation of a squall line and of orographic precipitation. Preprints, Conf. on Cloud Physics, Everett, WA, Amer. Meteor. Soc., 217-220.

Press, W. H., S. A. Teukolsky, W. T. Vetterling, and B. P. Flannery, 2007: Numerical Recipes in C. 3rd ed. Cambridge University Press, 1235 pp.

Rasmussen, E. A., and J. Turner, 2003: Polar Lows: Mesoscale Weather Systems in the Polar Regions. Cambridge University Press, $612 \mathrm{pp}$.

Reed, R. J., and C. N. Duncan, 1987: Baroclinic instability as a mechanism for the serial development of polar lows: A case study. Tellus, 39A, 376-384, https://doi.org/10.1111/j.16000870.1987.tb00314.x.

Reistad, M., Ø. Breivik, H. Haakenstad, O. J. Aarnes, B. R. Furevik, and J.-R. Bidlot, 2011: A high-resolution hindcast of wind and waves for the North Sea, the Norwegian Sea, and the Barents Sea. J. Geophys. Res., 116, C05019, https://doi.org/ 10.1029/2010JC006402.

Renfrew, I. A., and Coauthors, 2021: An evaluation of surface meteorology and fluxes over the Iceland and Greenland Seas in ERA5 reanalysis: The impact of sea ice distribution. Quart. J. Roy. Meteor. Soc., 147, 691-712, https://doi.org/10.1002/ qj.3941.

Rienecker, M. M., and Coauthors, 2011: MERRA: NASA's ModernEra Retrospective Analysis for Research and Applications. J. Climate, 24, 3624-2648, https://doi.org/10.1175/JCLI-D-1100015.1.

Rivas, M. B., and A. Stoffelen, 2019: Characterizing ERA-Interim and ERA5 surface wind biases using ASCAT. Ocean Sci., 15, 831-852, https://doi.org/10.5194/os-15-831-2019.

Rojo, M., G. Noer, and C. Claud, 2019: Polar low tracks in the Norwegian Sea and the Barents Sea from 1999 until 2019. PANGAEA, accessed 11 March 2021, https://doi.org/10.1594/ PANGAEA. 903058.

Saha, S., and Coauthors, 2010: The NCEP Climate Forecast System Reanalysis. Bull. Amer. Meteor. Soc., 91, 1015-1057, https:// doi.org/10.1175/2010BAMS3001.1.

— , and Coauthors, 2014: The NCEP Climate Forecast System version 2. J. Climate, 27, 2185-2208, https://doi.org/10.1175/ JCLI-D-12-00823.1.

Seity, Y., P. Brousseau, S. Malardel, G. Hello, P. Benard, F. Bouttier, C. Lac, and V. Masson, 2011: The AROMEFrance convective-scale operational model. Mon. Wea. Rev., 139, 976-991, https://doi.org/10.1175/2010MWR3425.1.

Sergeev, D., I. A. Renfrew, and T. Spengler, 2018: Modification of polar low development by orography and sea ice. Mon. Wea. Rev., 146, 3325-3341, https://doi.org/10.1175/MWR-D-18-0086.1.

Shimura, T., N. Mori, and M. A. Hemer, 2016: Variability and future decreases in winter wave heights in the western North
Pacific. Geophys. Res. Lett., 43, 2716-2722, https://doi.org/ 10.1002/2016GL067924.

Siebesma, A. P., and Coauthors, 2003: A large eddy simulation intercomparison study of shallow cumulus convection. J. Atmos. Sci., 60, 1201-1219, https://doi.org/10.1175/1520-0469(2003) 60<1201:ALESIS > 2.0.CO;2.

—, P. M. Soares, and J. Teixeira, 2007: A combined eddydiffusivity mass-flux approach for the convective boundary layer. J. Atmos. Sci., 64, 1230-1248, https://doi.org/10.1175/ JAS3888.1.

Simmons, A., and D. Burridge, 1981: An energy and angularmomentum conserving vertical finite-difference scheme and hybrid vertical coordinates. Mon. Wea. Rev., 109, 758-766, https://doi.org/10.1175/1520-0493(1981)109<0758:AEAAMC> 2.0.CO;2.

Smith, S. D., 1988: Coefficients for sea surface wind stress, heat flux, and wind profiles as a function of wind speed and temperature. J. Geophys. Res., 93, 15 467-15 472, https://doi.org/10.1029/ JC093iC12p15467.

Soares, P., P. Miranda, A. Siebesma, and J. Teixeira, 2004: An eddy-diffusivity mass-flux parameterization for dry and shallow cumulus convection. Quart. J. Roy. Meteor. Soc., 130, 3365-3383, https://doi.org/10.1256/qj.03.223.

Taillefer, F., 2002: CANARI. CNRM/GMAP Tech. Doc., 55 pp., http://www.umr-cnrm.fr/gmapdoc/IMG/ps/canari_doc_cy25t1.ps.

Takbash, A., I. Young, and $\varnothing$. Breivik, 2019: Global wind speed and wave height extremes derived from long-duration satellite records. J. Climate, 32, 109-126, https://doi.org/10.1175/JCLID-18-0520.1.

Uppala, S. M., and Coauthors, 2005: The ERA-40 Re-Analysis. Quart. J. Roy. Meteor. Soc., 131, 2961-3012, https://doi.org/ 10.1256/qj.04.176.

van Meijgaard, E., L. H. van Ulft, G. Lenderink, S. D. Roode, E. L. Wipfler, R. Boers, and R. van Timmermans, 2012: Refinement and application of a regional atmospheric model for climate scenario calculations of western Europe. KvR Rep. 054/12, 44 pp., http:// climexp.knmi.nl/publications/FinalReport_KvR-CS06.pdf.

Weill, A., and Coauthors, 2003: Toward a better determination of turbulent air-sea fluxes from several experiments. J. Climate, 16, 600-618, https://doi.org/10.1175/1520-0442(2003)016<0600: TABDOT $>2.0 . \mathrm{CO} ; 2$.

Wilks, D. S., 2006: Statistical Methods in the Atmospheric Sciences. 2nd ed. Academic Press, 627 pp.

Yano, J.-I., and Coauthors, 2018: Scientific challenges of convectivescale numerical weather prediction. Bull. Amer. Meteor. Soc., 99, 699-710, https://doi.org/10.1175/BAMS-D-17-0125.1.

Zahn, M., and H. von Storch, 2008: A long-term climatology of North Atlantic polar lows. Geophys. Res. Lett., 35, L22702, https://doi.org/10.1029/2008GL035769. 